Review article

\title{
An overview on biosynthesis and applications of extracellular pyocyanin pigment and its role in Pseudomonas aeruginosa pathogenesis
}

\author{
Alka Rani and Wamik Azmi* \\ Department of Biotechnology, Himachal Pradesh University, Shimla-171005 (H.P) India
}

Received October 30, 2019: Revised December 17, 2019: Accepted December 20, 2019: Published online December 30,2019

\begin{abstract}
Microbial pigments are chemical moieties capable of absorbing light in the visible range. The demand for natural colorants is increasing in every day as the present trend throughout the world is shifting towards the use of ecofriendly and biodegradable commodities. Among the natural sources, the pigment producing microorganisms hold a promising potential to meet present day challenges. Pigments are compounds that come in a wide variety and extensively used in industries. Industrial production of natural pigments by microbial fermentation has several advantages over extraction of pigments of plant origin, such as easy availability of inexpensive raw materials for their production, independence from crop seasons and their seasonal variations, etc. The Pseudomonas aeruginosa has ability to produce a number of redox-active phenazine compounds including pyocyanin. The pyocyanin pigment possesses antimicrobial, anticancerous, antioxidant, anti-inflammatory and immunosupperessive properties. This review covers the challenges and new insights into pyocyanin from $P$. aeruginosa with emphasis on the role of pyocyanin in $P$. aeruginosa infection with special attention to applications of pyocyanin pigment.
\end{abstract}

Key words: Pseudomonas aeruginosa, pigment, pyocyanin, antagonistic property

\section{Introduction}

Pseudomonas aeruginosa is a Gram-negative rod shaped bacterium (Moore et al., 2006), widely spread in soil, water and many other environments (Suthar et al., 2009). It is a common opporunistic and nosocomial pathogen capable of infecting immunocompromised human (Lyczak et al., 2000). P. aeruginosa produces variety of pigments as secondary metabolites with numerous of importance in various industrial fields. These secondary metabolites (pigments) are not essential for growth and proliferation of bacteria but for bacterial pathogenicity and biological control (Lau et al., 2004; Muller et al., 2009; Narsing Rao et al., 2017). Humans use secondary metabolites as medicines, flavorings and as biocontrol agents. Pyocyanin is one of the extracellular phenazine pigment, synthesized by the majority of strains of $P$. aeruginosa. Nearly $90-$ $95 \%$ of all isolates of $P$. aeruginosa produce pyocyanin pigment (Ran et al., 2003). Pyocyanin is a heterocyclic water soluble compound composed of two subunits of N-methyl-1hydroxyphenazine. Pyocyanin comes under the tricyclic phenazine class of compounds (Figure 1). Pyocyanin is a zwitter ion containing a phenol group and its zwitter ionic properties are believed to permit the toxin to easily permeate cell membranes (Hall et al., 2016).

Author for correspondence: Dr. Wamik Azmi

Professor, Department of Biotechnology, Himachal Pradesh University, Shimla-171005 (H.P) India

E-mail: wamikazmi@rediffmail.com

Tel.: +91-177-2831948

Copyright (C) 2019 Ukaaz Publications. All rights reserved.

Email: ukaaz@yahoo.com; Website: www.ukaazpublications.com

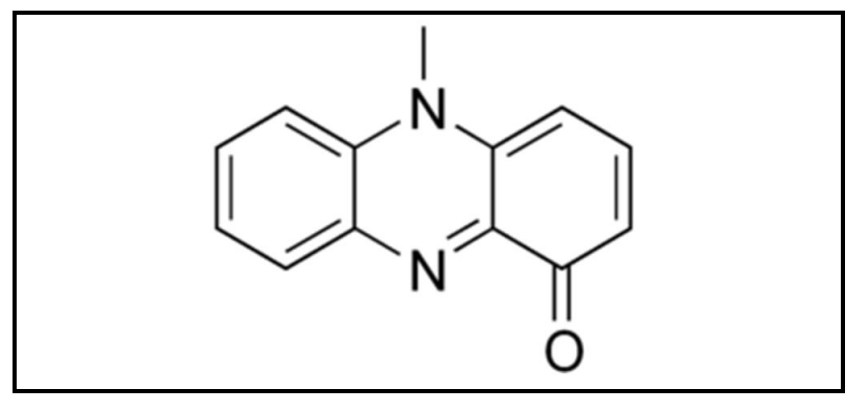

Figure 1: Structure of pyocyanin

The Shikimic acid pathway is used by the $P$. aeruginosa for the biosynthesis of pyocyanin where, shikimic acid acts as precursor (Figure 2). This pathway present only in bacteria, fungi, algae, parasites, plants but absent in animals. Microorganism and plants synthesize aromatic amino acids (phenylalanine, tyrosine, and tryptophan) and various pigments by this pathway during the stationary phase of microbial growth (Chin et al., 2001).

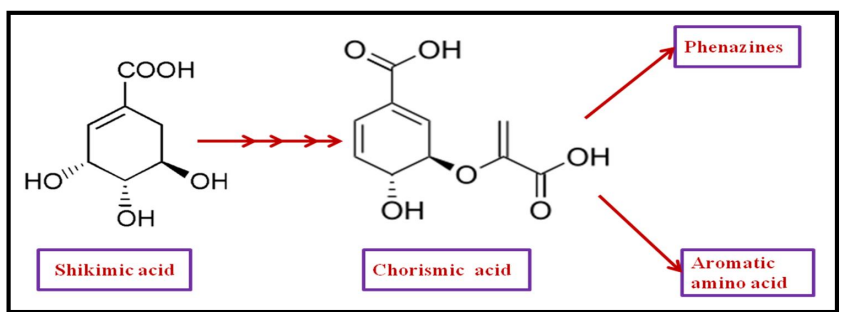

Figure 2: Phenazines from shikimic acid 
Pyocyanin is a potential factor that may enhance the survival of $P$. aeruginosa by increasing its capacity to compete with other microorganisms. A decrease in pathogenicity of $P$. aeruginosa was observed in vitro, when biosynthesis of pyocyanin was inhibited (Ho Sui et al., 2009). This suggests that pyocyanin is somewhat responsible for the initial colonization of $P$. aeruginosa in vivo. Pyocyanin pigment is a redox active secondary metabolite and has a characteristic feature of inhibiting many bacterial colonizations and fungal growth both in vivo and in vitro condition (Pai et al., 2010). P. aeruginosa strains, isolated from infections have been well studied by researchers for the production of pyocyanin (Hoadley et al., 1981; Hoadley and Ajello, 1982; McGowan et al., 1988).

Pyocyanin is a diffusible molecule which interacts with molecular oxygen intracellularly and disturbs redox cycling. These disturbances can result in the production of reactive oxygen species (ROS), such as superoxide and hydrogen peroxide which induce oxidative stress and damage of cells (Hassett et al., 1992). This natural ability of pyocyanin to modulate redox cycle and rise in oxidative stress appears to play vital role in its antimicrobial, antioxidant and in other applications. Researchers explored that the antimicrobial action of pyocyanin produced by Pseudomonas sp. TBH2 aid in controlling biocorrosive bacterial biofilm made by Bacillus sp. (Narenkumar et al., 2017). Pyocyanin has various pharmacological effects on prokaryotic cells (Ohfuji et al., 2004). It has been used to control phytopathogens (Sudhakar et al., 2013). It has also been reported for its application in aquaculture (Priyaja et al., 2014). A number of phenazines, however, do not exert cytotoxic effects in eukaryote cell and have been considered as anticancer or anti-infective agents (Laursen and Nielsen, 2004; Mavrodi et al., 2006). Pyocyanin pigment showed a more powerful interference in actively respiring cells such as tumor cells. It has been reported that phenazine derivatives can interfere with the function of topoisomerase I and II activities in eukaryotic cells (tumour cells) (Hassani et al., 2012). Pyocyanin is a redox active compound; it has also got application in biosensors because it can carry out transfer of electron between the electrode material and enzyme molecules. Such types of biosensors which are based on pyocyanin were also expected in different fields such as pharmaceutical, agricultural, and environment (Priyaja, 2013). Many researchers used phenazine compounds for the development of sensors and also in nanotechnology; for example, a derivative of phenazine was used to develop a $\mathrm{pH}$ sensor based on luminescence (Ryazanova et al., 2007). An amperometric sensor was developed for determination of hydrogen peroxide utilizing neutral red attached to multiwalled carbon nanotubes (Jeykumari and Narayanan, 2007). It also displays antibiofilm activity because of its capability to arrest the electron transport chain of many microorganisms (Kerr, 1994). In previous research, it has been reported that secretions from P. aeruginosa also inhibit formation of biofilm by several fungi, as well as other bacterial pathogens (Holcombe et al., 2010).

\section{Pigments}

The pigments of natural origin gain more attention in the market due to the development of interest in customers toward natural pigment and hazardous effects of synthetic pigments. In previous years, there is elevation in use of natural pigments in cosmetics, dyestuff, foodstuff and in pharmaceutical industry (Unagul et al., 2005). Natural color from flora and fauna are considered to be very safe because of non- carcinogenic, non-toxic and bio-degradable nature of pigments (Cristea and Vilarem, 2006). Plants and microorganism are the two main sources of natural pigments. Pigments come in various colors, some of which are water- soluble (Tibor, 2006) and some are solvent soluble. Large scale use of plants may lead to the loss of valuable species. Microbial pigments are preferred over the plant pigments because of their stable nature (Raisainen et al., 2002) and availability throughout the year for cultivation (Parekh, 2000).

\subsection{Microbial pigments}

Microorganisms are the most powerful creatures in existence and known to produce a wide variety of pigments; therefore they are promising source of food colorants (Aberoumand, 2011; Ahmad et al., 2012). Several numbers of pigments have been secreted by microorganisms (Fungi and bacteria) such as quinines, carotenoids, melanins, monascins, violancein, flavins (Duffose, 2006). Fungal (Table 1) and bacterial pigments (Table 2) have extensive applications, viz., antitumour, antioxidant, anti-inflammatory, antimicrobial beside act as coloring agent in cosmetic and food industry (Venil and Lakshmanaperumalsamy, 2009). They have an enormous advantage over plant pigments, including easy and rapid growth in low cost medium, easy processing, and growth that is independent of weather conditions. Fungi play vital role in production of pigment that can be used safely. Moreover, fungi are reported to produce larger amount of pigments (Kirti et al., 2014).

Table 1: Biologically active pigment produce by Fungi

\begin{tabular}{|c|c|c|c|c|}
\hline S.No. & Fungi & Pigment & Color & References \\
\hline 1 & Fusarium oxysporum & Anthraquinone & - & Nagia and El-Mohamedy, 2007 \\
\hline 2 & Aspergillus versicolor & Asperversin & - & Miao et al., 2012 \\
\hline 3 & Ashbya gossypi & Riboflavin & Yellow & Unagul et al., 2005; Hong et al., 2008; Powers, 2003 \\
\hline 4 & Talaromyces verruculosus & & Red & Chadni et al., 2017 \\
\hline 5 & Trichoderma, Aspergillus & Anthraquinone & - & Duran et al., 2002 \\
\hline 6 & Monascus sp. & $\begin{array}{l}\text { Monascin, ankaflavin } \\
\text { monascorubrin, rubropunctatin } \\
\text { monascorubramine, rubropuntamine }\end{array}$ & $\begin{array}{l}\text { Yellow } \\
\text { Orange, } \\
\text { Red }\end{array}$ & Feng et al., 2012 \\
\hline 7 & Stemphylium lycopersici & Anthraquinone & & Li et al., 2017 \\
\hline 8 & Penicillium herquei & Atronenetin & Yellow & Takahashi and Carvalho, 2010 \\
\hline 9 & Phycomyces blakesleeanus & b-carotene & Yellow-orange & Malik et al., 2012 \\
\hline 10 & Penicillium oxalicum & Anthraquinone & Red & Atalla et al., 2011 \\
\hline 11 & Trichoderma virens & Viridol & Yellow & Mukherjee and Kenerley, 2010 \\
\hline
\end{tabular}


Among microorganisms, bacteria have great potential to secrete diverse bioproducts (Figure 3). Natural pigment will be a boon for the preservation of biodiversity as they are biodegradable. Natural pigments can also serve the dual need for visually appealing colors and probiotic health benefits in food products (Nagpal et al., 2011). Pigment producing bacteria are ubiquitous and present in various ecological niches such as soil (Zhu et al., 2007), fresh water (Asker et al., 2008), rhizospheric soil (Peix et al., 2005), marine samples (Franks et al., 2005) and desert sand (Liu et al., 2009). Various researchers have been investigated the production and application of bacterial pigments (Joshi et al., 2003; Ahmad et al., 2012). By finding cheap and suitable growth medium which can reduce the cost of pigment production and increase its applicability for industrial production (Ahmad et al., 2012), the work on the bacterial pigments should be intensified.

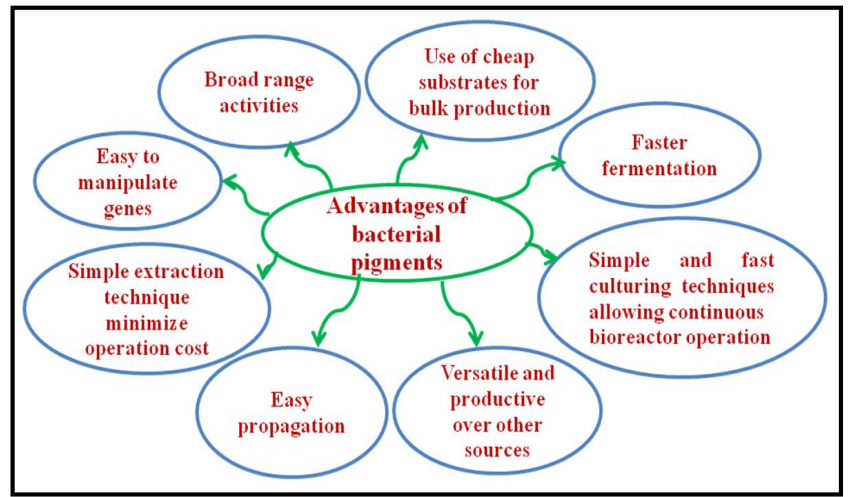

Figure 3: Various advantages of bacterial pigments

Table 2: List of some of bacterial pigments

\begin{tabular}{|l|l|l|l|l|}
\hline S. No. & Bacteria & Pigment & Color & References \\
\hline 1 & Chromobacterium sp. NIIST (MTCC 5522) & Violacein & & Sasidharan et al., 2015 \\
2 & Serratia rubidaed & Prodigiosin & Red & Moss, 2002 \\
3 & Pseudomonas aeruginosa & Pyocyanin & Blue & El-Fouly et al., 2015 \\
4 & Chromobacterium violaceum, Janthinobacterium lividum & Violacein & & \\
& Pseudoalteromonas luteoviolacea & & \\
\hline
\end{tabular}

\section{P. aeruginosa and its pigments}

P. aeruginosa is a Gram-negative bacterium, classified as an opportunistic pathogen, which cause diseases mostly in patients which are immunocompromised with cancer and patients suffering from severe burns and cystic fibrosis (CF). P. aeruginosa grows at optimum temperature of $25^{\circ}$ to $37^{\circ} \mathrm{C}$ and has the capacity to grow at $42^{\circ} \mathrm{C}$ which distinguish it from other Pseudomonas spp. It has the ability to grow under varieties of environmental conditions. It is facultative anaerobe that grows in normal atmosphere as well as in atmosphere deprived of adequate oxygen supply (hypoxic), therefore has colonized many natural and artificial environments. $P$. aeruginosa can achieve anaerobic growth with nitrate or nitrite as a terminal electron acceptor. By substrate-level phosphorylation, it is able to ferment arginine and pyruvate when oxygen, nitrate and nitrite are absent (Schobert and Jahn, 2010). Adaptation to microaerobic or anaerobic environments is required for certain lifestyles of $P$. aeruginosa. For example, thick layers of lung mucus and alginate surrounding mucoid bacterial cells can limit the diffusion of oxygen during lung infection in cystic fibrosis patients (Hassett, 1996; Worlitzsch et al., 2002; Cooper et al., 2003; Williams et al., 2007). It has few nutritional requirements and can adapt to conditions not tolerated by other microorganisms. The genome of $P$. aeruginosa is very large for a prokaryote, it provides an understanding of the metabolic and pathogenic mechanisms that underlie the success of this versatile pathogen, and it has become a model for understanding microbial genomic variation and evolution in chronic disease. The success of $P$. aeruginosa as an opportunistic pathogen is substantially due to the versatility and adaptability encoded in its genome (Paul, 2018).

Pseudomonas species is known for their ubiquity in the natural world and capacity to utilize a striking variety of organic compounds as energy sources and production of a remarkable array of secondary metabolites (Gross and Loeper, 2009). It produces different pigments (Figure 4) like pyocyanin (blue-green), pyoverdin (yellow-green and flurorescent), pyomelanin (light-brown) and pyorubin (red-brown) (Meyer, 2000). Pyoverdin is an iron binding molecule, produced by Pseudomonas species, that competes with transferring for host iron. It contributes to the virulence of Pseudomonas infections. Pyoverdin are fluorescent siderophores produced by pseudomonads. Pyomelanin synthesized from the catabolism of tyrosine or phenylalanine. Pyomelanin is formed abiotically outside the cell when excreted homogentisic acid autooxidizes to form benzoquinone acetic acid. Pyorubin is a bright red, water soluble, non fluorescent pigment produced by some strains of $P$. aeruginosa.

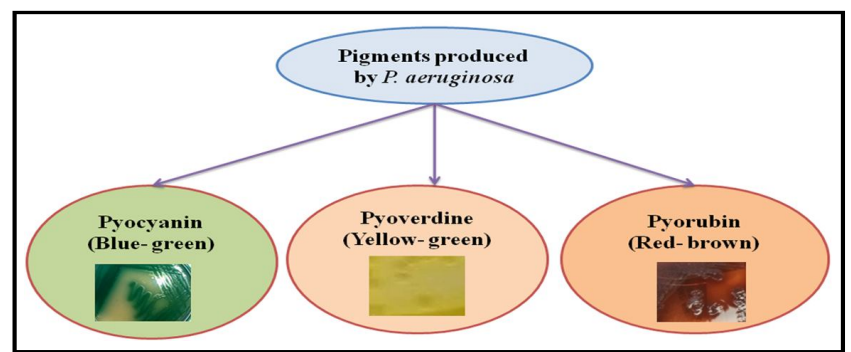

Figure 4: Pigments produced by $P$. aeruginosa

\section{Pyocyanin: history and its structure}

Since prehistoric times, the pigments have been used as coloring agents. Archaeologists uncovered various evidences which depict that early humans used pigments for decorative purposes, which prove that pigments has been used from pre-historic time (Kassinger, 2003). The pyocyanin pigment was first reported by Fordos from purulent wound dressings in 1859 (Fordos, 1859). Production of a blue-green pigment by bacteria, albeit without identification of the responsible compound, has been described by Schroeter (Schroeter, 1872). Gessard found that pyocyanin was produced by an aerobic motile bacterium (Gessard, 1882), which he named 'Bacillus pyocyaneus'. In 1900, Migula finally renamed pyocyanin-producing species by 'Pseudomonas aeruginosa', which is the name still in use today (Migula, 1900). By potentiometric 
studies, it has been found that zwitter ion nature of the pigment showed that pyocyanin acted as a reversible redox system in mixture with its reduced leuco derivative (Jensen and Holten, 1949). It also shows chameleon phenomenon due to its redox active states (Friedheim and Michaelis, 1931). Production of pyocyanin by $P$. aeruginosa was identified to be sensitive to the phosphate concentration in the growth media (King et al., 1954; Frank and DeMoss, 1959). Burton and his colleagues (1947) reported that amino acids could replace the peptone commonly claimed to be essential for good pigmentation. Since then more than 100 different phenazine compounds of microbial origin have been reported in the literature (Laursen and Nielsen, 2004; Mavrodi et al., 2006; Pierson and Pierson, 2010).

\section{Biosynthetic pathway}

Every color of the visible spectrum represented by phenazines, with a strong peak in the scale $250-290 \mathrm{~nm}$ and a weaker peak at $350-400 \mathrm{~nm}$ (Gerber, 1973). Oxidized, monovalently reduced or divalently reduced are three different states in which pyocyanin can exist. Biosynthesis of pyocyanin pigment occurred by a metabolic pathway, known as shikimic acid pathway (Figure 5). This pathway used by microrganism (bacteria, fungi, algae, parasites) and plants for the synthesis of aromatic amino acid and various pigments. This pathway is absent in animals. Synthesis of pyocyanin pigment occurred by sequential modification of various molecules in pathway (Herrmann and Weaver, 1999). Shikimic acid pathway is also known as aro pathway. Shikimic acid act as precursor molecule for synthesis of phenazines. Phenazine-1, 6-dicarboxylic acid believed to be the first phenazine structure in the pathway. It is formed by the condensation of two molecules of chorismic acid (Leisinger and Margraff, 1979). Amino deoxy isochorismate (ADIC) synthase enzyme used in this step, which convert chorismic acid to 2-amino-2-deoxyisochorismic acid (ADIC) by doing amination of chorismic acid. ADIC is then lead to the formation of trans-2, 3dihydro-3-hydroanthranilic acid (DHHA). For the formation of phenazine ring system, the condensation of two similar DHHA molecules is required. The two identical molecules react with each other by nucleophilic addition, dehydration and tautomerization to give 5,10-dihydroanthranilic acid, which is then undergo oxidation to form phenazine-1-carboxylic acid (PCA) (Figure 5).

The primary nitrogen source was glutamine and that the phenazine ring was constituted by a combination of two units of the same precursor for PCA biosynthesis (Romer and Herbert, 1982). The PCA leads to the synthesis of pyocyanin by hydroxylative decarboxylation mechanism. Mainly two steps involved in the pyocyanin synthesis from PCA (Figure 6). In first step, PCA is converted to 5-methylphenazine-1-carboxylic acid betaine by the enzyme PhzM (an S-adenosylmethionine dependent methyltransferase). There is transfer of methyl group to nitrogen atom of phenazine ring moiety. Second step lead to the formation of pyocyanin which is catalyzed by $\mathrm{PhzS}$, a FAD-dependent mono-oxygenase. This enzyme is responsible for hydroxylative decarboxylation of 5methylphenazine- 1 carboxylic acid betaine which leads to the formation of pyocyanin (Parsons et al., 2007). PhzM alone had no methylation activity toward PCA, but pyocyanin was produced in the presence of PhzS and NADH. PhzS has also been shown to act directly on PCA to produce phenazin-1-ol, but this compound was not a precursor for pyocyanin and, therefore PhzM must act before PhzS (Parsons et al., 2007). Formation of a complex between PhzM and PhzS would presumably prevent release of 5-methylphenazine1-carboxylate.

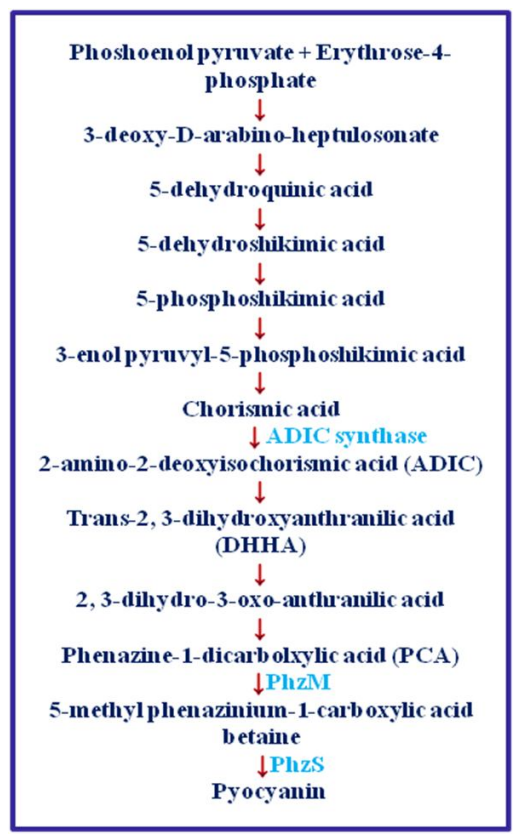

Figure 5: Shikimic acid pathway of pyocyanin biosynthesis in $P$. aeruginosa

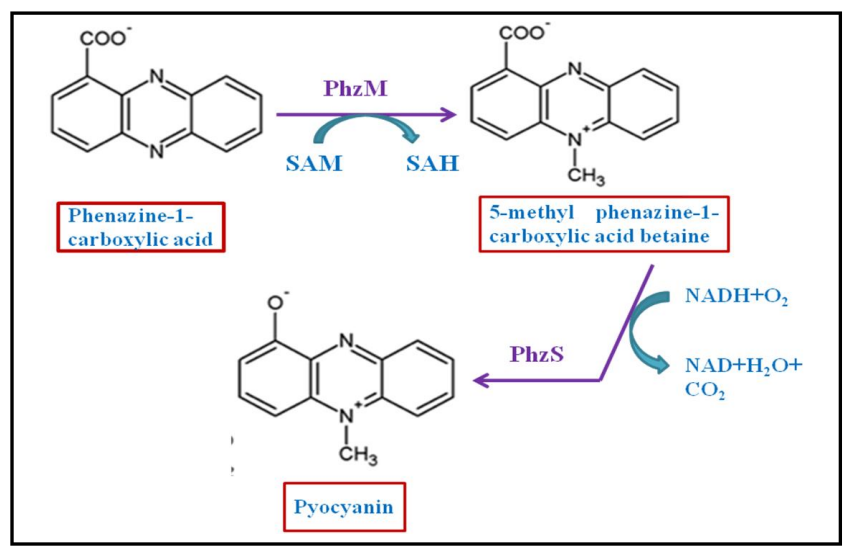

Figure 6: Role of PhzM and PhzS on pyocyanin synthesis

\section{Genetics and regulation of pyocyanin pathway}

Two specific genes must be functional for the production of pyocyanin by $P$. aeruginosa. Mvfr gene, produces a transcription factor, which then activates phzAB genes. These genes produce the molecule quinolone which then regulates operons 1 and 2 of PhzRABCDEFG which are the key to the synthesis of phenazine (Mavrodi et al., 2001). Pyocyanin biosynthesis begins with the conversion of chorismic acid to 2-amino-2-desoxyisochorismate (ADIC) by ADIC synthase, PhzE. In this reaction the enzyme PhzE catalyzes the loss of the hydroxyl group from $\mathrm{C} 4$ of chorismic acid as well as the transfer of an amine group from glutamine to form glutamic acid and 2-amino-2-desoxyisochorismic acid (ADIC) (Wulf and Parson, 2014). Following this, PhzD catalyzes the hydrolytic removal the pyruvate moiety from ADIC to form $(5 \mathrm{~S}, 6 \mathrm{~S})-6$-amino5-hydroxy-1,3-cyclohexadieve-1-carboxylic acid (DHHA). In the next step, PhzF catalyzes two steps: the abstraction of a hydrogen from $\mathrm{C} 3$ of DHHA, delocalization of the double bond system and 
reprotonation at $\mathrm{C} 1$ as well as enol tautomerization to form the highly unstable 6-amino-5-oxocyclohex-2-ene-1-carboxylic acid (AOCHC). From here two molecules of AOCHC are condensed by $\mathrm{PhzB}$ to form the tricyclic compound, hexahydrophenazine-1,6dicarboxylic acid (HHPDC). The product of this reaction, HHPDC, is unstable and spontaneously undergoes oxidative decarboxylation in an uncatalyzed reaction to form tetrahydrophenazine-1,6carboxylic acid (THPCA). In the final step of phenazine-1-carboxylic acid synthesis the enzyme PhzG catalyzes, the oxidation of THPCA to dihydro-phenazine-1-carboxylic acid. This is the last catalyzed step in the production of PCA, the last step is an uncatalyzed oxidation of DHPCA to PCA (Wulf and Parson, 2014). The conversion of PCA to pyocyanin is achieved in two enzymatic steps: firstly, PCA is methylated on N5 to 5-methylphenazine-1carboxylate betaine by the enzyme PhzM using the cofactor Sadenosyl-L-methionine and secondly, PhzS catalyzes the hydroxylative decarboxylation of this substrate to form the final product, pyocyanin (Mavrodi et al., 2001).

\section{Pyocyanin in P. aeruginosa infection}

The isolates of $P$. aeruginosa have been classified into 20 serotypes by the International Antigenic Typing Scheme. The lipopolysaccharide (LPS) of $P$. aeruginosa is less toxic than that of other gram-negative rods, facilitating its establishment of chronic infections by eliciting a low inflammatory response (Prince, 2012). P. aeruginosa is a metabolically versatile bacterium that can cause a wide range of severe opportunistic infections in patients with serious underlying medical conditions. $P$. aeruginosa colonize human body sites, with a preference for moist areas, such as the perineum, axilla, ear, nasal mucosa and throat as well as stools. The prevalence of colonization by $P$. aeruginosa in healthy subjects is usually low. It mainly infects patients with burns or those that are immunocompromised and it is one of the main causes of nosocomial infections (Lyczak et al., 2002) (Table 3).

Table 3: Common infection caused by $P$. aeruginosa

\begin{tabular}{|l|l|l|}
\hline S. No. & Pseudomonal Infection & Major risk factors \\
\hline 1 & Urinary tract & Use of urinary catheter \\
2 & Soft tissues & Burns, open wounds, postsurgery \\
3 & Respiratory/pneumonia & Old age, chronic obstructive pulmonary disease, cystic fibrosis, mechanical ventilation \\
4 & Otitis externa (swimmer's ear) & Tissue injury, water blockage in ear canal \\
5 & Bacteremia & Immunocompromised \\
6 & Keratitis (corneal infection) & Extended contact lens wear, contaminated contact lens solution \\
7 & Otitis media folliculitis (hot tub rash) & Improperly cleaned hot tubs \\
\hline
\end{tabular}

According to data from the Centre for Disease Control and Prevention National Nosocomial Infection Surveillance System, in the USA, $P$. aeruginosa was the second most common cause of nosocomial pneumonia, the third most common cause of nosocomial urinary tract infections, and the seventh most common cause of nosocomial bacteraemia (NNIS, 1999). In Europe, P. aeruginosa was found to be the third most common isolate from nosocomial infections in intensive care units (Vincent et al., 1995). Mortality rates ranging from $40 \%$ to more than $60 \%$ have been reported in bacteremic nosocomial pneumonia and in ventilator associated pneumonia (Crouch Brewer et al., 1996; Mayhall, 1997; Rello et al., 1997). In the United States, P. aeruginosa is among the most common hospital pathogens and is the second most common pathogen isolated from patients with ventilator-associated pneumonia (VAP) (Hidron et al., 2008 ).

There is substantial difference in phenotype of $P$. aeruginosa isolated from acute infections and from chronic infections (Smith et al., 2006). Isolates from acute infections express a wealth of virulence factors, while in contrast, many isolates from chronic CF lung infections lack some of the most inflammatory bacterial features, such as flagella and pili, and downregulate other virulence mechanisms such as the type 3 secretion system (Hogardt and Heesemann, 2010). P. aeruginosa uses several virulence factors to establish chronic respiratory infections in bronchiectasis, chronic obstructive pulmonary disease and cystic fibrosis patients (Murphy, 2008; Cohen and Prince, 2012). Cystic fibrosis is one of the most major and common fatal genetic disorders among the Caucasian population. It affects approximately 30,000 individuals in the United States alone. P. aeruginosa produces a large number of exoproducts (Table 4), including elastase, alkaline protease, the LasA protease, hemolysin, rhamnolipids and pyocyanin (Lyczak et al., 2002) to disrupt the host immune responses and cause cytoskeletal reorganization.
Table 4: Factors enhancing the pathogenicity of $P$. aeruginosa

\begin{tabular}{|l|l|l|}
\hline S. No. & Factors & Role \\
\hline 1 & Adhesions & Attachment \\
2 & Alginate production & Mucoid layer \\
3 & Exotoxin A & Inhibit host protein synthesis \\
4 & Exoenzyme S & Interferes with phagocytic killing \\
5 & Elastolytic activity & Degrades elastin \\
6 & Phospholipase C & Damage tissue \\
7 & Pyocyanin & Damage tissue by ROS \\
8 & Antibiotic resistance & Complicates therapy \\
\hline
\end{tabular}

Pyocyanin is a zwitter ion that can easily penetrate biological membranes. By interfering with several cellular functions in host cells, pyocyanin promotes virulence including electron transport, cellular respiration, energy metabolism, gene expression and innate immune mechanisms. It causes oxidative stress to the host, disrupting host catalase and mitochondrial electron transport (Lau et al., 2004). Purified pyocyanin induced apoptosis in vitro in neutrophils as well as inhibit the phagocytosis of apoptotic bodies by macrophages (Lau et al., 2004; Bianchi et al., 2008). It is also able to modulate the expression of the chemokines IL- 8 and RANTES by airway epithelial cells (Denning et al., 1998) and suppress cilia beating.

It is readily recovered in large quantities from the sputum of patients with CF infected by P. aeruginosa (Wilson et al., 1988) and from ear secretions of $P$. aeruginosa mediated chronic otitis media (Reimer, 2000). Inspite of this, the exact contribution of pyocyanin in the pathogenesis of $P$. aeruginosa mediated diseases has remained controversial. However, studies on the role of pyocyanin in virulence in vivo using alternative model hosts (Mahajan-Miklos et al., 1999; Cao et al., 2001; Lau, 2003) and mice (Lau et al., 2004) 
have revealed that pyocyanin has crucial roles in $P$. aeruginosa infection.

Many studies have concluded that pyocyanin has a derogatory effect in cystic fibrosis (CF) which enables $P$. aeruginosa to persist in the $\mathrm{CF}$ lung. Pyocyanin in vitro has the ability to interfere with functions such as ciliary beating and, therefore cause dysfunction of epithelium as the ciliary are required for sweeping mucus up the throat (Kanthakumar et al., 1993). Additionally, neutrophil apoptosis, (Usher et al., 2002) immunoglobulin release from B-lymphocytes and interleukin (IL-8) release (Denning et al., 1998) and CCL5 are all impaired by pyocyanin causing the immune system of the lung to be weakened. In vivo studies have shown that in the presence of pyocyanin, the fungal growth is inhibited. The fungicidal mechanism is the activation of $\mathrm{NAD}(\mathrm{P}) \mathrm{H}$ to induce a redox active cycle to produce reactive oxygen intermediates. This allows $P$. aeruginosa to have a competitive advantage as it may dominate over other micro-organisms in the CF lung (Kerr et al., 1998). The intracellular level of ATP is also reduced by pyocyanin causing further damage to CFTR which are already impaired in cystic fibrosis. CFTR channels depend on ATP for two main purposes. First, the binding and hydrolysis of ATP has to occur at two domains of nucleotide binding for the channel to move between its open and closed conformation. Second, phosphorylation of CFTR by protein kinase A II should occur in order for the channel to be operational. PKA II is activated by cAMP which is secreted from ATP. Both these processes are impaired when ATP is depleted by pyocyanin (Ostedgaard et al., 2001). If $P$. aeruginosa utilize pyocyanin to its advantage in competing with other bacterial strains in the same ecological niche, it must, therefore, have a mechanism for its own protection or immunity against the bactericidal agent it produces. This immunity could be via higher concentrations of SOD (sodium dismutase) and catalase or by lack of permeability. Hassan and Fridorich (1980) reported that $P$. aeruginosa made $62 \%$ higher catalase when grown under conditions conducive for pyocyanin production. However, the level of SOD was slightly lower. They also checked the effect of pyocyanin on the rate of cyanide-resistant respiration in $P$. aeruginosa and found it to be nonresponsive to pyocyanin. The respiration of $P$. aeruginosa was generally resistant to cyanide. Thus, 8 to $10 \mathrm{mM}$ was required to inhibit the respiration by $91.3 \%$, and $0.134 \mathrm{mM}$ pyocyanin caused this cyanide-resistant respiration to rise from 8.7 to $14.8 \%$. This increase is very moderate compared to that observed in E. coli. These results tentatively indicate that $P$. aeruginosa is not as permeable to pyocyanin as is $E$. coli, and they show that the organism makes higher catalase to protect against $\mathrm{H}_{2} \mathrm{O}_{2}$ that might be generated outside the cells via extracellular auto-oxidation of pyocyanin. They presumed that $P$. aeruginosa actively secretes pyocyanin while keeping its intracellular level low by a combination of low permeability and active extrusion (Hassan and Fridorich, 1980). Pyocyanin also inhibits prostacyclin release and can inactivate human V-ATPases (involved in receptor-mediated endocytosis), a1-protease inhibitor (which modulates serine protease activity, including neutrophil elastase) and nitric oxide (which influences blood flow, blood pressure and immune functions).

\section{Antimicrobial resistance of $\boldsymbol{P}$. aeruginosa infection}

Antimicrobial resistance is the capacity of microbes to stop an antimicrobial substance such as antibiotics, antivirals and antimalarials from working against it. Because of this standard treatments become ineffective, infections persist and may spread to others. The $P$. aeruginosa is a leading source of infection in hospitals, with few available treatment options. The infections caused by $P$. aeruginos $a$ are very difficult to treat due to its intrinsic ability to resist many classes of antibiotics as well as its ability to acquire resistance. There are three mechanisms responsible for resistance and all these known mechanisms of antibiotic resistance can be displayed by this bacterium (intrinsic, acquired and adaptive); sometimes all within the same isolate. Despite the use of combination of drug therapies, resistance rates increased rapidly (Moore and Flaws, 2011). There are many new drugs available in the market to treat $P$. aeruginosa infections but there has been a return to the use of older drugs such as polymyxins that had previously fallen out of favor due to wide reports of toxic side effects (Livermore, 2002). Despite the reports of nephrotoxicity and neurotoxicity, for patients with $\mathrm{CF}$ suffering recurrent infections of multidrug-resistant bacteria, colistin (a polymyxin drug) has been routinely administered via inhalation for the past 15 years (Falagas and Kasiakou, 2006), demonstrating that the antibiotic resistance problem has been influencing therapeutic choices for many years.

\section{Inhibition of pyocyanin production to combat $P$. aeruginosa infection}

P. aeruginosa is an opportunistic pathogen that causes infections in immune-compromised hosts, burn victims, individuals in intensive care and patients with CF. The lungs of nearly all CF patients are chronically colonised by $P$. aeruginosa, which significantly reduces life expectancy and it is the leading cause of morbidity and mortality for CF patients. P. aeruginosa is a versatile pathogen, possessing a number of adaptations such as; an outer membrane of low permeability, a multitude of efflux pumps and various degradative enzymes that disable antibiotics. These features combine to limit the range of effective treatment options. The ability of $P$. aeruginosa to cause infection is depend on the secretion of agents termed, virulence factors, such as toxins and adhesion molecules, that actively cause damage to host tissues. Pyocyanin produced by several clinical strains of $P$. aeruginosa from pulmonary and extrapulmonary infections (Schaber et al., 2004; García-Contreras et al., 2015; Guendouze et al., 2017) as well as in environmental strains (Grosso-Becerra et al., 2014) and is found in high concentrations up to $100 \mathrm{M}$ (Caldwell et al., 2009) in the lung of cystic fibrosis patients.

Pyocyanin act as both a virulence factor and a quorum sensing signalling molecule for P. aeruginosa (Lau et al., 2004; Karatuna and Yagci, 2010). In P. aeruginosa, virulence is controlled through quorum sensing (Allen et al., 2014). Virulence and quorum sensing are connected by signaling pathways. Quorum sensing pathways rely on the production, release and detection of small molecule signals that regulate virulence genes ( $\mathrm{Ng}$ and Bassler, 2009). It has been identified by some researcher that pathogen-associated proteins have homology only with pathogenic bacteria and not with non-pathogens (Ho Sui et al., 2009). Such types of proteins are more likely to have virulence-related functions. The list of identified pathogen-associated proteins has been included in components of the phenazine biosynthesis pathway. Therefore, pyocyanin biosynthesis is an attractive target for anti-infective drug intervention. Researchers have directed increasing attention in recent years to 'disarm' the pathogenicity of bacteria rather than kill them. This can be done by targeting virulence using anti-infective or anti-virulence drugs. 
It has been reported that thiolactone 1 which is a structural analog of the native acyl-homoserine lactone, is a potent inhibitor of pyocyanin production in vivo. The thiolactone 1 interacts with both LasR and RhlR but the inhibition through RhlR results in the key anti-virulence effects of the compound (O'Loughlin et al., 2013). LasR is a transcriptional activator in P. aeruginosa, required for the transcription of the genes for elastase and LasA protease associated with virulence whereas, RhlR is a regulatory gene encodes the transcriptional regulator RhlR which has central role in quorum sensing response.

\section{Biodegradation of pyocyanin pigment}

The environmental degradation of the residual pyocyanin became an important factor as pyocyanin has been used in aquaculture system. Yang and his colleagues reported the biodegradation of PCA, the precursor of pyocyanin by soil organisms Sphingomonas sp. DP58. Sphingomonas sp. DP58 consume PCA as the sole source of carbon and nitrogen and completely degrade it within $40 \mathrm{~h}$ (Yang et al., 2007). Hill and Johnson (1969) reported the microbial transformation of phenazines by Aspergillus sclerotiorum. Chen and his colleague conducted the study on intermediates or metabolites produced out of this degradation (Chen et al., 2008).

Biodegradation of pyocyanin is esteemed by the presence of phenolic character in the compound and phenolics are the best substrates for peroxidases. The oxidation of pyocyanin leads to its inactivation and become non-toxic and the reaction is irreversible (Reszka et al., 2004). The study on photosensitized oxidation and inactivation showed that pyocyanin could be partially inactivated through photochemical oxidation. The resulting product is a poorer free radical generator and, therefore a less efficient stimulant of oxidative processes. These results suggest that photosensitization could be a potentially useful method for inactivation and possibly for detoxification (Reszka et al., 2004).

\section{Applications of pyocyanin}

\subsection{Pyocyanin as an anti-oxidant}

Oxidative stress is an important risk factor in the pathogenesis of numerous chronic diseases. Free radicals and other reactive oxygen species are recognized as agents involved in the pathogenesis of sicknesses such as asthma, inflammatory arthropathies, diabetes, Parkinson's and Alzheimer's diseases, cancers as well as atherosclerosis. Reactive oxygen species are also said to be responsible for the human aging (Kanwar et al., 2009; Chiavaroli et al., 2011). Antioxidants are natural molecules that may prevent or delay cell damage. It inhibits the oxidation of other molecules. Oxidation is a process that releases free radicals, leading to chain of reaction that may destroy cells. Free radical scavenging activity of pyocyanin was estimated by DPPH (2, 2- diphenyl-1 picrylhydrazyl hydrate) radical scavenging assay (Liyana and Shahidi, 2005). It is a free radical, contain an unpaired electron. This assay is very simple and rapid to perform and very effective for the evaluation of antioxidants by spectrophotometry (Huang et al., 2005). DPPH contains an odd electron because of which it has strong absorption maximum at $517 \mathrm{~nm}$ and is purple in color. The conversion of color from purple to yellow is observed when an odd electron of DPPH paired with hydrogen from a radical scavenging oxidant to form the reduced DPPH-H (2, 2- diphenyl-1picrylhydrazine).
It has been reported that pyocyanin produced from $P$. aeruginosa BTRY1 strain has higher free radical scavenging activity of $80 \%$ at $0.2 \mu \mathrm{g} / \mathrm{ml}$, even at very much lower concentration than that of ascorbic acid (Laxmi and Bhat, 2016). This is a positive indication for the safe use of product as compound showed very high antioxidant activity at very minute concentration of pyocyanin (Liyana and Shahidi, 2005). Chandran (2014) evaluated the antioxidant activity of pyocyanin pigment and it was found to be $55 \%$ at $500 \mu \mathrm{g} / \mathrm{ml}$ concentration. Pyocyanin extracted from $P$. aeruginosa CGR-3 showed $38 \%$ of free radical scavenging activity at $4.25 \mu \mathrm{g} / \mathrm{ml}$ pyocyanin concentration (Rani et al., 2018). The phenolic compounds present in plants also shown to have antioxidant potential. The polyphenols like methanolic extract of Abutilon indicum leaves showed very strong antioxidant activity in vitro (Das et al., 2019).

\subsection{Pyocyanin as an antibacterial compound}

$P$. aeruginosa, which exerts broad antagonistic activity against other bacterial and fungal pathogens through the production of a secondary metabolite-pyocyanin. Although Pseudomonads are well reported for their pathogenicity, the ability of this bacterium to produce antimicrobial pigment opened the door of using this as biological control agent (Devnath et al., 2017). Pyocyanin has antibiotic activities and it is also able to coordinate the response of microbial communities to changes in the environment. Small attempts have been made to analyze the relation between pyocyanin and its inhibitory action. Since year 1940, it has been reported that pyocyanin possess antibacterial properties (Waksman and Woodruff, 1940). Pyocyanin pigment was also known as Colicin because it inhibit the growth of E. coli. During lysis of bacteria, protein fraction was released which showed the antimicrobial properties of pyocyanin pigment (Young, 1947). According to Hassan and Fridorich (1980), exposure of E. coli cultures exposed to pyocyanin pigment caused the depletion of oxygen supply to the cells which leads to the production of hydrogen peroxide $\left(\mathrm{H}_{2} \mathrm{O}_{2}\right)$ and also divert the electron flow, causing toxicity to the cells.

Pyocyanin, a water soluble bio-active compound, has the capacity to arrest the electron transport chain, exhibits antifungal activity (Wilson et al., 1987) and antibacterial activity. Pyocyanin increases intracellular oxidant stress and exhibits a redox cycle under aerobic conditions. This leads to reactive oxygen species (ROS) production such as superoxide and hydrogen peroxide; these ROS compounds are capable of inhibiting microbial growth (Denning et al., 1998; Das and Manefield, 2012). The bactericidal effect of purified pyocyanin pigment depends on its concentration in all cases (Baron and Rowe, 1981). Baron and Rowe (1981) reported that only 2.9 $\mu \mathrm{g}$ of purified pigment is sufficient for the inhibition of bacterial growth. Pyocyanin showed its antibacterial action on both Gram negative as well as Gram positive bacteria.

Pyocyanin showed bactericidal action against many pathogenic bacteria like Salmonella paratyphi, E. coli and Klebsiella pneumonia (Saha et al., 2008). Pyocyanin pigment also showed antibacterial action on food spoilage bacteria like L. monocytogenes and B. cereus. It has been reported in various papers that Gram-positive bacteria were more susceptible than Gram-negative bacteria. Variation in the lipid content of cell wall of Gram-positive and Gram-negative bacteria may be responsible for the variation in the sensitivity of pyocyanin 
antibiotic. El-Fouly and colleagues in (2015) reported that highest minimum inhibitory concentration (MIC) of purified pyocyanin was $50 \mu \mathrm{g} / \mathrm{ml}$ whereas lowest MIC was $20 \mu \mathrm{g} / \mathrm{ml}$ against $E$. coli. Pyocyanin from P. aeruginosa DSO-129 demonstrated for antibacterial effect on organisms like $S$. aureus, Staphylococcus epidermis, Bacillus subtilis, Micrococcus luteus and S. cerevisiae (Rahman et al., 2009). There has been another report related to antimicrobial action of pyocyanin against pathogens. The pigment showed very effective against organisms like $E$. coli, Acinetobacter, S. aureus and Streptococcus pneumonia (Sweden, 2010).

The mechanism of action of the pigment on fungus is same as that of mechanism of antibacterial action. Pyocyanin yield obtained from $P$. aeruginosa OSh1 was recorded $76.11 \mu \mathrm{g} / \mathrm{ml}$ showed higher antibacterial activities at 28.3, 37.3 and $21 \mathrm{~mm}$ against Grampositive, Gram-negative bacteria and fungi respectively (Barakat et al., 2015). Pyocyanin obtained from culture supernatants of $P$. aeruginosa isolates (grown in peptone water liquid medium) reached about $62.8 \mu \mathrm{g} / \mathrm{ml}$ and showed more antimicrobial action on Grampositive bacteria (inhibition zones $=15 \mathrm{~mm}$ in diameter) than on Gram-negative bacteria (inhibition zones $=14 \mathrm{~mm}$ in diameter) (ElShouny et al., 2011). The antimicrobial activity of pyocyanin of $P$. aeruginosa CGR-3 inhibited E. coli, Salmonella paratyphi, Klebsiella sp. Alternaria sp. but Aspergillus niger remain resistant to pyocyanin (Rani et al., 2018).

Several groups reported the in vitro inhibition of yeast growth by P. aeruginosa (Hughes et al., 1973; Kerr, 1994) and there are reports which suggest that inhibition of yeast growth by $P$. aeruginosa in vivo in patients with (Hughes et al., 1973) and without cystic fibrosis (Kerr, 1994). Pyocyanin obtained from P. aeruginosa, isolated from the sputum of CF patient, also seize the growth of fungi like Candida albicans and Aspergillus niger. When $P$. aeruginosa was co-cultured with $C$. albicans, the $P$. aeruginosa synthesized large amounts of pyocyanin and even the growth of $C$. albicans was inhibited (Hogan and Kolter, 2002; Gibson et al., 2009; Hassanein et al., 2009). Inhibition of growth of A. fumigatus by pyocyanin was reported to be of dose dependent but occurred at much higher levels (>19 $\mu \mathrm{g} / \mathrm{well})$. Pal and his colleagues in (2006) reported that pyocyanin showed antibiotic activity in vivo on Candida sp. grown on Sabroud's dextrose agar. Pyocyanin $(0.6 \mu \mathrm{g} /$ well) and 1-hydroxyphenazine $(9.5 \mu \mathrm{g} /$ well $)$ inhibited the growth of additional yeast species known to cause human infection in the well plate assay (C. krusei, C. keyfr, C. guillermondii, C. tropicalis, C. glabrata, C. lusitaniae, C. parapsilosis, C. pseudotropicalis and S. cerevisiae).

\subsection{Pyocyanin as antibiofilm agent}

Bacteria within biofilm are thousand times more resistant to conventional antibiotic treatment and responses of host immune. This makes it extremely difficult to eradicate biofilm. Any group of microorganisms, in which cells adhered to each other and often also to the surface comprises biofilm and these cells become enclosed in slimy extracellular matrix that is formed of extracellular polymeric substances (EPS). An EPS is a sugars, proteins and nucleic acids (such as DNA) network. It helps the microbes to stick together in a biofilm. Many disease outbreaks were found to be linked with biofilms formation and there is always threat to human health because of food borne diseases. Biofilms became a major problem in food industry. The reason that biofilm formation is a great cause of concern is that, within a biofilm, bacteria are more resistant to antibiotics and other major disinfectants that we used to control them. Therefore, searching for novel compounds or strategies to inhibit biofilm formation or disperse preformed biofilm is needed (Wu et al., 2015). It has been reported that biofilm formed by many fungi and other pathogenic bacteria was inhibited by secreation from $P$. aeruginosa (Holcombe et al., 2010). There are many reports that $P$. aeruginosa itself can inhibit growth and biofilm formation. Bacterial pigments used for controlling biofilm are reported to have antioxidant activity along, which in addition to absence of cytotoxicity, make them useful in food industry for control of food borne pathogens.

Microtitre plate assay with crystal violet staining was used to test in vitro biofilm formation and its inhibition. Generally, 96 well microtitre plates were used for antibiofilm assay. The antibiofilm activity of compound was expressed using two techniques: scanning electron microscopy (SEM) and confocal laser scanning microscopy (CLSM). Biofilm inhibitory concentration (BIC) is defined as the lowest concentration of the compound which inhibits biofilm formation. Laxmi and Bhat (2016), reported that pyocyanin pigment at very low concentration $\left(2 * 10^{-2} \mathrm{ng} / \mu \mathrm{l}\right)$ biofilm inhibitory concentration) has antibiofilm activity against biofilms formed by Vibrio diabolicus and Salmonella enteritidis and more than $80 \%$ reduction in biofilm was achieved. Pyocyanin $(1.245 \mu \mathrm{g} / \mathrm{ml})$ from $P$. aeruginosa BTRY 1 was able to bring about $80 \%$ reduction of biofilm in $S$. warneri BTDF2, followed by $60 \%$ inhibition in the EPS production of B. casei BTDF1, $40 \%$ in B. pumilus BTMY2, $36 \%$ in Bacillus sp. BTSD1, 28\% in B. niacini BTDP3 and $11.6 \%$ in case of $B$. altitudinis BTMW1. However, biofilm formation by P. aeruginosa, Micrococcus luteus and Geobacillus stearothermophilus could not be controlled.

Pyocyanin $\left(2 * 10^{-2} \mathrm{ng} / \mu \mathrm{l}\right)$ in combination with bacteriocin $(3.8 \mathrm{ng} /$ $\mu 1)$ showed around $70 \%$ biofilm inhibition in case of $B$. casei BTDF1 and $S$. warneri BTDF2 and 30-40\% in case of Micrococcus luteus and Geobacillus stearothermophilus. Whereas, with rhamnolipids $(1.2 \mathrm{ng} / \mu \mathrm{l})$ it has been reported that both $B$. casei BTDF1 and $B$. pumilus BTMY2 were inhibited to $70 \%$, but it does not inhibit the biofilm of $P$. aeruginosa BTRY1. The BIC values of the bioactive compounds used in the study were in nanogram quantities against the tested food pathogens. This clearly indicates the immensely potent strength of the pyocyanin in biofilm control compared to the current antibiofilm strategies like antibiotic treatments. Besides pigments, phytochemicals has been also used as antibiofilm agent (Kanwar et al., 2018) alone or in combination with antibiotics.

\subsection{Pyocyanin as antitumour agent}

Pyocyanin act as cytotoxic compound by increasing the intracellular reactive oxygen species. Pigment generates superoxide $\left(\mathrm{O}^{2-}\right)$ and hydrogen peroxide $\left(\mathrm{H}_{2} \mathrm{O}_{2}\right)$ reactive oxygen species on reduction by $\mathrm{NADH}$ and NADPH in the cells and the reduced form of pigment transfer electron to $\mathrm{O}_{2}$. This is referred as intracellular redox cascade of pyocyanin. The reactive oxygen species formed around and within the mitochondria (O'Malley et al., 2003). Pyocyanin prevent the breakdown of hydrogen peroxide $\left(\mathrm{H}_{2} \mathrm{O}_{2}\right)$ by inhibiting the activity of catalase by reducing the expression of gene encoding catalase. This leads to the increase in level of reactive oxygen species 
indirectly (Ricciardolo et al., 2006). A very toxic reactive nitrogen species (RNS) are formed when superoxide reacts with nitric oxide. The RNS and ROS both act together to damage proteins, DNA, phospholipids of cells and finally cause death to the cells (Nishi and Forgac, 2002).

Hassani and his colleagues (2012) also studied the cytotoxic effect of pyocyanin from mutant and wild type strains of $P$. aeruginosa on RD cells. Zhao and his colleagues (2014) studied the proliferation of HepG2 cells in the presence of $10 \mu \mathrm{g} / \mathrm{ml}$ pyocyanin. According to their study, a nine day treatment by pyocyanin led to $67 \%$ decline in HepG2 cell numbers compared to the control. They demonstrated that cell death induced by pyocyanin arises from oxidative stress due to ROS augmentation, damage to DNA, activation of caspase- 3 and the acceleration of senescence and apoptosis. Aylin and his colleague (2018) reported the cytotoxic effects of pyocyanin on human pancreatic cancer cell line (Panc-1). According to their study there was inhibition of $98.69 \pm 0.23$ and $89.88 \pm$ $1.86 \%$ of $6 \mathrm{mg} / \mathrm{ml}$ of pyocyanin extracted from clinical and soil isolates of $P$. aeruginosa respectively. Priyaja and colleagues (2014), demonstrated the cytotoxic effect of pyocyanin pigment on L132, RTG2 and Sf9 cell lines. Among these cell lines L132, a human embryonic lung epithelial cell line showed highest response to pigment than others. Further, $80 \%$ of cell viability remain even at high concentration of pigment indicate that it is safe to consume the food supplemented with pyocyanin (Laxmi and Bhat, 2016). The cytotoxic effect of pyocyanin pigment was checked by MTT assay (Arung et al., 2009). The pyocyanin extracted from Pseudomonas sp. MCC 3145 has cytostatic potential and was found to arrest the growth of Hep-G2, SK-MEL-2, A-549, and HeLa cancer cells. The DNA intercalation-based cytostatic activity of pyocyanin on various human cancer cell lines suggests that this molecule could be explored for use in therapeutics (Patil et al., 2017).

The measurement of cell viability after treatment with different concentrations of pyocyanin to establish the cytotoxic effect has been done by MTT (Diphenyltetrazolium Bromide) assay (Arung et al., 2009). This is a colorimetric assay method which measures the reduction of yellow MTT by mitochondrial succinate dehydrogenase to formazon. The MTT enters the cells and passes into the mitochondria where it has been reduced to an insoluble, dark purple colored formazan product.

\subsection{Pyocyanin in biosensor}

Biosensors are analytical devices that convert a response into an electrical signal with biological system. For more accurate determination of glucose concentration, an amperometric biosensor system using a screen printed electrode and pyocyanin as mediator were also developed. Pyocyanin which exists in the oxidized form was reduced by the reaction between glucose oxidase and glucose. The reduced form was a linear relationship between sensor output currents and glucose concentrations (Ohfuji et al., 2004). For detecting water toxicity, a novel mediator-free method based on genetically modified bacteria was also developed where genetically modified (G) bacteria, P. aeruginosa was selected as the biosensor strain was used as the indicator. An amperometric biosensor system using pyocyanin as a mediator was developed by (Ohfuji et al., 2004) for a more accurate determination of glucose. Therefore, the biosensors using pyocyanin was also expected to apply to some fields such as medicine, food and enviornment. Quintessentially biosensors must be highly specific, independent of physical parameters such as $\mathrm{pH}$ and temperature and should be reusable (Mehrotra, 2016). The toxicity response of G P. aeruginosa to 3, 5-dichlorophenol (3, 5-DCP) was measured electrochemically and spectroscopically (Yu et al., 2017). The present study provided convenient, sensitive method for water toxicity detection and extended biosensing supplication of the genetically modified bacterium.

\subsection{Microbial fuel cells}

The devices which convert chemical energy into electricity are known as microbial fuel cells (MFCs). In MFCs, electrochemically active bacteria $(\mathrm{EAB})$ oxidized a series of carbon source including organic substrate or even pollutants in wastewater and transfer the generated electron to anodes (Rabaey and Rozendal, 2010; Logan and Rabaey, 2012; Lovley, 2012 ). EAB play an important role in the power generation of MFCs for its ability of generating electrons during metabolism and transferring electrons through the cell membrane from the cell to the anode (Liu et al., 2012; Yong et al., 2013). Bacteria used in MFCs system Shewanella, Pseudomonas and Geobacter. Out of these bacteria, P. aeruginosa gets much attention, since it can produce highly redox-active endogenous electron shuttles such as pyocyanin (Rabaey et al., 2005, Yong et al., 2014a, Yong et al., 2014b). Riboflavin and pyocyanin electron shuttles has been proved to be more fruitful (Hernandez and Newman, 2001; Rabaey et al., 2005; Wen et al., 2011). Pyocyanin excreted by $P$. aeruginosa is responsible for carrying electron through cell membrane due to which its concentration in the anodic culture directly effect the power generation efficiency (Yong et al., 2011).

It has been reported that sophorolipid was an effective additive to improve the performance of $P$. aeruginosa inoculated MFC. The improvement is due to the increased electron shuttle (pyocyanin) production and the enhanced membrane permeability, which directly promoted the electron shuttle, mediated extracellular electron transfer (EET) (Shen et al., 2014). MFCs has been studied for their various applications such as treatment of waste (Yong et al., 2014b), biosensors (Mansfeld, 2007), renewable energy (Logan, 2009) etc. Despite the applications, poor energy yield has been a serious issue hindering the efficiency of MFCs. There was a study which has been attempted to increase pyocyanin yield from environmentally isolate strain of $P$. aeruginosa. Physiochemical and nutritional parameters were tinkered and yield of pyocyanin was enhanced by formulating bacterial growth media. The study can help in improvement MFC bioelectricity yield by enhanced pyocyanin production in a $P$. aeruginosa inoculated MFC (Rashid and Andleeb, 2018).

\subsection{Application of pyocyanin in aquaculture}

Aquaculture is defined as the farming of fish, molluscs, crustaceans, etc. and it is the cultivation of populations of saltwater and freshwater under controlled conditions. Aquaculture is the multibillion dollar industry on global scale and fastest growing food sector and, looked upon as the high protein resource to meet the nutritional requirements of the increasing population. The swing in aquaculture development is towards magnification (BondadReantaso et al., 2005). However, the commercial production by aquaculture are obstructed by diseases caused by bacteria, fungi, 
parasites, viruses and other undiagnosed and emerging pathogens In this context, antibiotics engaged the central stage as control agents. This common strategy to control diseases over a period of time there is antibiotic resistance and horizontal transfer of resistant genes from fish pathogens to humans. In this scenario, several alternatives remedies for the prevention and control of diseases in aquaculture have been put forth, such as immunostimulants, vaccines and probiotics (Gomez et al., 2007).

A large number of microorganisms harm the aquaculture environment which include Gram-negative species (Aeromonas, Flavobacterium, Pseudomonas, Achromobacter and Vibrio) and Gram-positive (Corynebacterium, Micrococcus and Bacillus). Vibriosis is a major disease caused by Vibrio spp. which is ubiquitous in aquaculture associated with all cultured species including fish, molluscs and crustaceans (Verdonck et al., 1997; Thompson et al., 2001; Vandenbergh et al., 2003; Jayaprakash et al., 2006).

Pseudomonads are usual occupant of the aquatic environment including shrimp culture ponds (Otta et al., 1999) and are oftenly related with gills, skin and intestinal tract of live fish (Cahill, 1990). However, in vitro inhibition of fish and prawn pathogens have been shown by the many bacterial isolates which are common members of the non pathogenic microbiota of fish and shellfish culture systems (Jayapraksh et al., 2005). It was stated that certain strains of bacteria have the ability to control pathogens by means of competitive exclusion or by the secretion of inhibitory compounds for, e.g., bacteria associated with Artemia and prawn culture systems (Verschuere et al., 2000). The disease prevention has received much attention in order to control the fish and shellfish pathogenic vibrios, particularly by use of non pathogenic bacterial isolates (Sugita et al., 1998; Rengpipat et al., 2000).

Pyocyanin can be applied as eco-friendly drug in aquaculture system as it is biodegradable and can be readily oxidized. For marine prawn, Pseudomonas acts as a potent probiotic as it caused growth inhibition of a number of pathogens such as Salmonella, Photobacterium demenselae, Staphylococcus aureus, Vibrio vulnificus, V. parahaemolyticus, $V$. harveyi, V. fluvialis and Aeromonas (Oblinger and Kreft, 1990; Vijayan et al., 2006). Hai and Fotedar (2009), reported that $P$. synxantha and $P$. aeruginosa are most effective probiotic in inhibiting bacteria isolated from Penaeus latisulcatus.

\section{Conclusion}

Pyocyanin is one of the toxins produced by the P. aeruginosa for enhancing its pathogenesis. Pyocyanin enhance the pathogenesis by inhibiting the growth of competitive microorganisms of $P$. aeruginosa. Besides this, pyocyanin gain attention due to its various applications in pharmaceutical, agriculture, biosensors, environmental, etc. Many new antibiotics have been developed by pharmaceutical industries, but finding new broad spectrum antimicrobial agents is still a priority because of resistant bacterial infections. The pyocyanin possesses effective antimicrobial activity against many pathogens which are multidrug resistant. Inhibition of such pathogens by pyocyanin pigment showed its importance and potentiality as an antimicrobial drug. Researchers explored this antibacterial property of pyocyanin produced by Pseudomonas sp. TBH2 in controlling biocorrosive bacterial biofilm formed by
Bacillus sp. In addition to this, pyocyanin pigment showed cytotoxic effect in vitro on cancerous cell line at very minute concentration but it has been repored that pyocyanin has no toxic effect on normal cell lines. The antibiofilm activity of the pyocyanin against multiple antibiotic resistant food pathogens expands their efficacy for applications in food industry. This can be used to control several other active food pathogens if applied in the food. More applications need to be explored with in vivo studies in order to establish firmly the positive effects of pyocyanin in clinical and therapeutics science.

\section{Acknowledgements}

The author Alka Rani acknowledges the Senior Research fellowship from Indian Council of Medical Research, Govt. of India, New Delhi for this study and Himachal Pradesh University, Summerhill, Shimla, India.

\section{Conflict of interest}

The authors declare that there are no conflicts of interest in the course of conducting the research. Both the authors had final decision regarding the manuscript and decision to submit the findings for publication.

\section{References}

Aberoumand, A. (2011). A review article on edible pigments properties and sources as natural biocolorants in foodstuff and food industry. World Journal of Dairy Food Sciences, 6:71-78.

Ahmad, W.A.; Ahmad, W.Y.W.; Zakaria, Z.A. and Yusof, N.Z. (2012). Application of bacterial pigments as colorant. Springer Briefs in Molecular Science, pp:57-74.

Allen, R.C.; Popat, R.; Diggle, S.P. and Brown, S.P. (2014). Targeting virulence: Can we make evolution-proof drugs? Nature Reviews Microbiology, 12:300-308.

Arung, E.T.; Wicaksono, B.D.; Handoko, Y.A.; Kusuma, I.W.; Yulia, D. and Sandra, F. (2009). Anti-cancer properties of diethylether extract of wood from sukun (Antocarpus altils) in human breast cancer (T47D) cells). Tropical Journal of Pharmceutical Research, 8:317-324.

Asker, D.; Bappu, T. and Ueda, K. (2008). Nubsella zeaxanthini faciens gen. nov., sp. nov., a zeaxanthin producing bacterium of the family Sphingobacteriaceae isolated from freshwater. International Journal of Systematic and Evolutionary Microbiology, 58:601-606.

Atalla, M.M.; Elkhrisy, E.A.M. and Asem, M.A. (2011). Production of textile reddish brown dyes by fungi. Malaysian Journal of Microbiology, 7:33-40.

Barakat, K.; Mattar, M.Z.; Sabae, S.Z. and Darwesh, O.M. (2015). Production and characterization of bioactive pyocyanin pigment by marine Pseudomonas aeruginosa OSh1. Research Journal of Pharmaceutical, Biological and Chemical Sciences, 6:933-943.

Baron, S.S. and Rowe, J.J. (1981). Antibiotic action of pyocyanin. Antimicrobial Agents and Chemotherapy, 20:814-820.

Bianchi, S.M.; Prince, L.R.; McPhillips, K.; Allen, L.; Marriott, H.M.; Taylor, G.W.; Hellewell, P.G; Sabroe, I.; Dockrell, D.H.; Henson, P.W. and Whyte, M.K. (2008). Impairment of apoptotic cell engulfment by pyocyanin, a toxic metabolite of Pseudomonas aeruginosa. American Journal of Respiratory and Critical Care Medicine, 177:35-43.

Bondad-Reantaso, M.G.; Subasinghe, R.P.; Arthur, J.R.; Ogawa, K.; Chinabut, S.; Adlard, R.; Tan, Z. and Shariff, M. (2005). Disease and health management in Asian aquaculture. Veterinary Parasitology, 132: 249-272. 
Burton, M.O.; Eagles, B.A. and Campbell, J.J.R. (1947). The amino acid requirements for pyocyanin production. Canadian Journal of Research, 25:121-128.

Cahill, M.M. (1990). Bacterial flora of fishes. Microbial Ecology, 19:21-41.

Caldwell, C.C.; Chen, Y.; Goetzmann, H.S.; Hao, Y.; Borchers, M.T.; Hassett, D.J.; Young, L.R.; Mavrodi, D.; Thomashow, L. and Lau, G.W. (2009). Pseudomonas aeruginosa exotoxin pyocyanin causes cystic fibrosis airway pathogenesis. The American Journal of Pathology, 175:2473-2488.

Cao, H.; Krishnan, G.; Goumnerov, B.; Tsongalis, J.; Tompkins, R. and Rahme, L.G. (2001). A quorum sensing associated virulence gene of Pseudomonas aeruginosa encodes a LysR-like transcription regulator with a unique self-regulatory mechanism. Proceedings of the National Academy of Sciences of the United State of America, 98:14613-14618.

Chadni, Z; Rahaman, M.H.; Jerin, I.; Hoque, K.M.F. and Reza, M.A. (2017) Extraction and optimisation of red pigment production as secondary metabolites from Talaromyces verruculosus and its potential use in textile industries. Mycology, 8:48-57.

Chandran, M.; Duraipandi, V.; Yuvaraj, D.; Vivek, P. and Parthasarathy. (2014). Production and extraction of bacterial pigments from novel strains and their applications. Journal of Pharmaceutical, Biological and Chemical sciences, 5:584-593.

Chen, K.; Hu, H.; Wang, W.; Zhang, X. and Xu, Y. (2008). Metabolic degradation of phenazine-1-carboxylic acid by the strain Sphingomonas sp. DP58: Then identification of two metabolites. Biodegradation, 19:659-667.

Chiavaroli, V.; Giannini, C.; De Marco, S.; Chiarelli, F. and Mohn, A. (2011). Unbalanced oxidant-antioxidant status and its effects in pediatric diseases. Redox Report, 16:101-107.

Chin-A-Woeng, T.F.C.; Thomas-Oates, J.E.; Lugtenbrg, B.J.J. and Bloemberg, G.V. (2001). Introduction of the phzH gene of Pseudomonas chlororaphis PCL1391 extends the range of biocontrol ability of phenazine-1carboxylic acid producing Pseudomonas spp strains. Molecular Plant-Microbe Interactions, 14:1006-1015.

Cohen, T.S. and Prince, A. (2012). Cystic fibrosis: A mucosal immunodeficiency syndrome. Nature Medicine, 18:509-519.

Cooper, M.; Tavankar G.R. and Williams, H.D. (2003). Regulation of expression of the cyanide-insensitive terminal oxidase in Pseudomonas aeruginosa. Microbiology, 149:1275-1284.

Cristea, D. and Vilarem, G. (2006). Improving light fastness of natural dyes on cotton yarn. Dyes and Pigments, 70:238-245.

Crouch, B.S.; Wunderink, R.G.; Jones, C.B. and Leper, K.V. (1996). Ventilatorassociated pneumonia due to Pseudomonas aeruginosa. Chest, 109:1019-1029.

Das, K.; Khan, M.S.; Namratha, N.; Swetha, R. and Gezici, S. (2019). Comparative phytochemical screening, elemental content and chromatographic evaluation for detection and quantification of polyphenolic compounds for strong antioxidant activity of various extracts of Abutilon indicum (Link) Sweet leaves. Ann. Phytomed., 8:36-44.

Das, T. and Manefield, M. (2017). Pyocyanin promotes extracellular DNA release in Pseudomonas aeruginosa. PLoS ONE, 7:e46718. doi: 10.1371/journal.pone.0046718.

Denning, G.; Wollenweber, L.; Railsback, M.; Cox, C.; Stoll, L. and Britigan, B. (1998). Pseudomonas pyocyanin increases interleukin- 8 expression by human airway epithelial cells. Infection and Immunity, 66:5777-5784.

Devnath, P.; Uddin Md, K.; Ahamed, F.; Hossain Md, T. and Manchur, M.A. (2017) Extraction, Purification and characterization of pyocyanin produced by Pseudomonas aeruginosa and evaluation of its antimicrobial activity. International Research Journal of Biological Sciences, 6:1-9.
Duffose, L. (2006). Microbial production of food grade pigments, food grade pigments. Food Technology and Biotechnology, 44:313321 .

Duran, N.; Teixeira, M.F.S.; De Conti, R. and Esposito, E. (2002). Ecologicalfriendly pigments from fungi. Critical Reviews in Food Science and Nutrition, 42:53-66.

El-Fouly, M.Z.; Sharaf, A.M.; Shahin, A.A.M.; El-Bialy, H.A. and Omara, A.M.A. (2015). Biosynthesis of pyocyanin pigment by Pseudomonas aeruginosa. Journal of Radiation Research and Applied Science, 8:36-48.

El-Shouny, W.A.; Al-Baidani, A.R.H. and Hamza, W.T. (2011). Antimicrobial Activity of pyocyanin produced by Pseudomonas aeruginosa isolated from surgical wound-infections. International Journal of Pharmacy and Medical Sciences, 1:01-07.

Falagas, M.E. and Kasiakou, S.K. (2006). Toxicity of polymyxins: A systematic review of the evidence from old and recent studies. Critical Care, 10:R27. doi: 10.1186/cc3995.

Feng, Y.; Shao, Y. and Chen, F. (2012). Monascus pigments. Applied Microbiology and Biotechnology, 96:1421-1440.

Fordos, J. (1859). Receuil des Travaux de la Societe d'Emulation pour les Sciences Pharmaceutiques, 3:30-38.

Frank, H. and DeMoss, R.D. (1959). On the biosynthesis of pyocyanin. Journal of Bacteriology, 77:776-782.

Franks, A.; Haywood, P.; Holmstrom, C.; Egan, S.; Kjelleberg, S. and Kumar, N. (2005). Isolation and structure elucidation of a novel yellow pigment from marine bacterium Pseudoalteromonas tunicate. Molecules, 10:1286-1291

Friedheim, E. and Michaelis, L. (1931). Potentiometric study of pyocyanin. The Journal of Biological Chemistry, 91:355-368.

García-Contreras, R.; Perez-Eretza, B.; Jasso-Chavez, R.; Lira-Silva, E.; RoldanSanchez, J.A.; Gonzalez-Valdez, A.; Soberón-Chávez, G; Coria-Jiménez, R.; Martínez-Vázquez, M.; Alcaraz, L.D.; Maeda, T. and Wood, T.K. (2015). High variability in quorum quenching and growth inhibition by furanone C-30 in Pseudomonas aeruginosa clinical isolates from cystic fibrosis patients. Pathogens and Disease, 73:ftv040. doi: 10.1093/ femspd/ftv0 40 .

Gerber, N.N. (1973). Microbial Phenazines. In: CRC handbook of microbiology. Volume III: Microbial products. Eds: Laskin A.I. and Lechevalier, H.A., CRC Press, 33:329-332.

Gessard, C. (1882). Sur les colorations bleues et vertes des linges: A pansements. Compte Rendu de l'Academic des Siences, 94:536-538.

Gibson, J.; Sood, A. and Hogan, D.A. (2009). Pseudomonas aeruginosa-Candida albicans interactions; localization and fungal toxicity of a phenazine derivatives. Applied Environmental Microbiology, 75:504-513.

Gomez, R.; Geovanny, D.; Balczar, J.L. and Shen, M.A. (2007). Probiotics as control agents in aquaculture. Journal of Ocean University of China, 6:76-79.

Gross, H. and Loper, J.E. (2009). Genomics of secondary metabolite production by Pseudomonas spp. Natural Product Reports, 26: 1408-1446.

Grosso-Becerra, M.V.; Santos-Medellin, C.; Gonzalez-Valdez, A.; Mendez, J.L.; Delgado, G.; Morales-Espinosa, R.; Servin-Gonzalez, L.; Alcaraz, L.D. and Soberon-Chavez, G. (2014). Pseudomonas aeruginosa clinical and environmental isolates constitute a single population with high phenotypic diversity. BMC Genomics, 15:318-332.

Guendouze,A.; Plener, L.; Bzdrenga, J.; Jacquet, P.; Remy, B.; Elias, M.; Lavigne, J.P.; Daudé, D. and Chabrière, E. (2017). Effect of quorum quenching lactonase in clinical isolates of Pseudomonas aeruginosa and comparison with quorum sensing inhibitors. Frontier Microbiology, 8:227. doi: $10.3389 /$ fmicb. 2017.00227 . 
Hai, V. N. and Fotedar, R. (2009). Comparison of the effects of the prebiotics (Bio- $\operatorname{Mos}{ }^{\circledR}$ and $\beta$-1,3-D-glucan) and the customised probiotics (Pseudomonas synxantha and P. aeruginosa) on the culture of juvenile western king prawns (Penaeus latisulcatus Kishinouye, 1896). Aquaculture, 289:310-316.

Hall, S.; McDermott, C.; Anoopkumar-Dukie, S.; McFarland, A.J.; Forbes, A.; Perkins, A.V.; Davey, A.K.; Chess-Williams, R.; Kiefel, M.J.; Arora, D. and Grant, G.D. (2016). Cellular effects of pyocyanin, a secreted virulence factor of Pseudomonas aeruginosa. Toxins, 8:E236. doi: 10.3390/ toxins 8080236 .

Hassan, H. M. and Fridorich, I. (1980). Mechanism of the antibiotic action of pyocyanin. Journal of Bacteriology, 141:156-163.

Hassanein, W.A.; Awny, N.M.; El-Mougith, A.A. and Salah El-Dein, S.H. (2009) Characterization and antagonistic activities of metabolites produced by Sha8. Journal of Applied Science Research, 5:392-403.

Hassani, H.; Hasan, H.; Al-Saadi, A.; Ali, A. and Muhammad, M. (2012). A comparative study on cytotoxicity and apoptotic activity of pyocyanin produced by wild type and mutant strains of Pseudomonas aeruginosa. European Journal of Experimental Biology, 2:1389-1394.

Hassett, D.J. (1996). Anaerobic production of alginate by Pseudomonas aeruginosa: Alginate restricts diffusion of oxygen. Journal of Bacteriology, 178:7322-7325.

Hassett, D.J.; Charniga, L.; Bean, K.; Ohman, D.E. and Cohen, M.S. (1992) Response of Pseudomonas aeruginosa to pyocyanin: Mechanisms of resistance, antioxidant defenses, and demonstration of a manganesecofactored superoxide dismutase. Infection and Immunity, 60:328-336.

Hernandez, M. and Newman, D. (2001). Extracellular electron transfer. Cellular and Molecular Life Sciences CMLS, 58:1562-1571.

Herrmann, K.M. and Weaver, L.M. (1999). The shikimate pathway. Annual Review of Plant Physiology and Plant Molecular Biology, 50:473-503.

Hidron, A.; Edwards, J.R.; Patel, J.; Horan, T.C.; Sievert, D.M.; Pollock, D.A. and Fridkin S.K. (2008). NHSN (National Healthcare Safety Network) annual update: Antimicrobial-resistant pathogens associated with healthcare-associated infections: Annual summary of data reported to the National Healthcare Safety Network at the Centers for Disease Control and Prevention, 2006-2007. Infection Control and Hospital Epidemiology, 29:996-1011.

Hill, J.C. and Johnson, G.T. (1969). Microbial transformation of phenazines by Aspergillus sclerotiorum. Mycologia, 61:452-467.

Ho Sui, S.J.; Fedynak, A.; Hsiao, W.W.; Langille, M.G. and Brinkman, F.S. (2009) The association of virulence factors with genomic islands. Nucleic Acids Research, 4:e8094. doi: 10.1371/journal.pone.0008094.

Hoadley, A.W. and Ajello, G. (1982). Some characteristic of fluorescent Pseudomonads isolated from surface waters and capable of growth at $41^{\circ} \mathrm{C}$. Canadian Journal of Microbiology, 18:1769-1773.

Hoadley, A.W.; McCoy, E. and Rohlich, G.A. (1981). Untersuchungen ube Pseudomonas aeruginosa in Oberflachengewassern. I. Quellen. Archives of Hygiene Bakteriology, 152:328-338.

Hogan, D.A. and Kolter, R. (2002). Pseudomonas-Candida interaction: An ecological role for virulence factors. Science, 296:2229-2232.

Hogardt, M. and Heesemann, J. (2010). Adaptation of Pseudomonas aeruginosa during persistence in the cystic fibrosis lung. International Journal of Medical Microbiology, 300:557-562.

Holcombe, L.J.; McAlester, G.; Munro, C.A.; Enjalbert, B.; Brown, A.J.P.; Gow, N.A.R.; Ding, C.; Butler, G.; O'Gara, F. and Morrissey, J.P. (2010). Pseudomonas aeruginosa secreted factors impair biofilm development in Candida albicans. Microbiology, 156:1476-1486.

Hong, M.Y.; Seeram, N.P.; Zhang, Y. and Heber, D. (2008). Anticancer effects of Chinese red yeast rice versus monacolin $\mathrm{K}$ alone on colon cancer cells. The Journal of Nutritional Biochemistry, 19:448-458.
Huang, D.J.; Ou, B.X. and Prior, R.L. (2005). The chemistry behind antioxidant capacity assays. Journal of Agriculture and Food Chemistry, 53:1841-1856

Hughes, W. T. and Kim, H. K. (1973). Mycoflora in cystic fibrosis: Some ecologic aspects of Pseudomonas aeruginosa and Candida albicans. Mycopathologia, 50:261-269.

Jayaprakash, N.S.; Pai, S.S.; Anas, A.; Preetha, R.; Philip, R. and Singh, I.S.B. (2005). A marine bacterium, Micrococcus MCCB 104, antagonistic to vibrios in prawn larval rearing systems. Disease of Aquatic Organisms, 68:39-45.

Jayaprakash, N.S.; Rejish, K.V.J.; Philip, R. and Singh, I.S.B. (2006). Vibrios associated with Macrobrachium rosenbergii (De Man, 1879) larvae from three hatcheries on the Indian southwest coast. Aquaculture Research, 37:351-358.

Jensen, K.A. and Holten, C.H. (1949). The dipole moment of pyocyanin. Acta Chemica Scandinavica, 3:1446-1447.

Jeykumari, D. and Narayanan, S. (2007). Covalent modification of multi walled carbon nanotubes with neutral red for the fabrication of an amperometric hydrogen peroxide sensor. Nanotechnology, 18: $125501-125510$.

Joshi, V.; Attri, D.; Bala, A. and Bhushan, S. (2003). Microbial Pigments. Indian Journal of Biotechnology, 2:362-369.

Kanthakumar, K.; Taylor, G; Tsang, K.; Cundell, D.; Rutman, A.; Smith, S.; Jeffery, P.; Cole, P. and Wilson, R. (1993). Mechanism of action of Pseudomona aeruginosa pyocyanin on human ciliary beat in vitro. Infection and Immunity, 61:2848-2853.

Kanwar, J.R.; Kanwar, R.K.; Burrow, H. and Baratchi, S. (2009). Recent advances on the roles of NO in cancer and chronic inflammatory disorders. Current Medicinal Chemistry, 16:2373-2394.

Karatuna, O. and Yagci, A. (2010). Analysis of quorum sensing-dependent virulence factor production and its relationship with antimicrobial susceptibility in Pseudomonas aeruginosa respiratory isolates. Clinical Microbiology and Infection, 16:1770-1775.

Kassinger, R.G. (2003). Dyes: From sea snails to synthetics. Minneapolis, MN: Millbrooke Press, Inc.

Kerr, J.; Taylor, G.; Rutman, A.; Hoiby, N.; Cole, P. and Wilson, R. (1998). Pseudomonas aeruginosa pyocyanin and 1-hydroxyphenazine inhbit fungal growth. Journal of Clinical Pathology, 52:385-387.

Kerr, J.R. (1994). Inhibition of fungal growth by Pseudomonas aeruginosa and Pseudomonas cepacia isolated from patients with cystic fibrosis. Journal of Infection, 28:305-310.

King, E.O.; Ward, M.K. and Raney, D.E. (1954). Two simple media for the demonstration of pycocyanin and fluorescin. Journal of Laboratory and Clinical Medicine, 4:301-307.

Kirti, K.; Amita, S.; Priti, S.; Kumar, A.M. and Jyoti, S. (2014). Colorful world of microbes: Carotenoids and their applications. Journal of Advances in Biology, pp:1-13. doi.org/10.1155/2014/837891.

Kanwar, K.; Thakur, P. and Azmi, W. (2018). Use of phytochemicals as emerging strategy for control of biofilm formed by pathogens. Ann. Phytomed., 7:25-37.

Lau, G.W. (2003). The Drosophila melanogaster toll pathway participates in resistance to infection by the gram-negative human pathogen Pseudomonas aeruginosa. Infection and Immunity, 71:4059-4066.

Lau, G.W.; Hassett, D.J.; Ran, H. and Kong, F. (2004). The role of pyocyanin in Pseudomonas aeruginosa infection. Trends in Molecular Medicine, 10:599-606.

Lau, G.W.; Hassett, D.J.; Ran, H.; Kong, F. and Mavrodi, D. (2004). Pseudomonas aeruginosa pyocyanin is critical for lung infection in mice. Infection and Immunity, 72:4275-4278. 
Laursen, J. and Nielsen, J. (2004). Phenazine natural products: Biosynthesis, synthetic analogue and biological activity. Chemical Reviews, 104:1663-1685.

Laxmi, M. and Bhat, S.G. (2016). Characterization of pyocyanin with radical scavenging and antibiofilm properties isolated from Pseudomonas aeruginosa strain BTRY1. 3 Biotech., 6:27-32.

Leisinger, T. and Margraff, R. (1979). Secondary metabolites of the fluorescent pseudomonads. Microbiology Reviews, 4:422-442.

Li, F.; Xue, F. and Yu, X. (2017). GC-MS, FTIR and Raman analysis of antioxidant components of red pigments from Stemphylium lycopersici. Current Microbiology, 74:532-539.

Liu, M.; Peng, F.; Wang, Y.; Zhang, K.; Chen, G. and Fang, C. (2009). Kineococcus xinjiangenesis sp. nov., isolated from desert sand. International Journal Systematic and Evolutionary Microbiology, 59:1090-1093.

Livermore, D.M. (2002). Multiple mechanisms of antimicrobial resistance in Pseudomonas aeruginosa: Our worst nightmare? Clinical Infectious Diseases, 34:634-640.

Liyana, P.C.M. and Shahidi, F. (2005). Antioxidant activity of commercia soft and hard wheat (Triticum aestivum $\mathrm{L}$.) as affected by gastric $\mathrm{pH}$ conditions. Journal of Agricultural and Food Chemistry, 53:429-443.

Logan, B.E. (2009). Exoelectrogenic bacteria that power microbial fuel cells. Nature Reviews Microbiology, 7:375-381.

Logan, B.E. and Rabaey, K. (2012). Conversion of wastes into bioelectricity and chemicals by using microbial electrochemical technologies. Science, 337:686-690.

Lovley, D.R. (2012). Electromicrobiology. Annual Reviews of Microbiology, 66:391-409.

Lyczak, J.B.; Cannon, C.L. and Pier, G.B. (2000). Establishment of Pseudomonas aeruginosa infection: Lessons from a versatile opportunist. Microbes and Infection, 2:1051-1060.

Lyczak, J.B.; Cannon, C.L. and Pier, G.B. (2002). Lung infections associated with cystic fibrosis. Clinical Microbiology Reviews, 15:194-222.

Mahajan-Miklos, S.; Tan, M.W.; Rahme, L.G. and Ausubel, F.M. (1999). Molecular mechanisms of bacterial virulence elucidated using a Pseudomonas aeruginosa-Caenorhabditis elegans pathogenesis model. Cell, 96:47-56

Malik, K.; Tokkas, J. and Goyal, S. (2012). Microbial pigments: a review. International Journal of Microbial Research Technology, 1:361-365.

Mansfeld, F. (2007). The interaction of bacteria and metal surfaces. Electrochimica Acta, 52:7670-7680.

Mavrodi, D.V.; Blankenfeldt, W. and Thomashow, L.S. (2006). Phenazine compounds in fluorescent Pseudomonas spp. biosynthesis and regulation. Annual Review of Phytopathology, 44:417-445.

Mavrodi, D.V.; Bonsall, R.F.; Delaney, S.M.; Soule, M.J.; Phillips, G. and Thomashow, L.S. (2001). Functional Analysis of Genes for Biosynthesis of Pyocyanin and Phenazine-1-Carboxamide from Pseudomonas aeruginosa PAO1. Journal of Bacteriology, 183: 6454-6465.

Mavrodi, D.V.; Ksenzenko, V.N.; Bonsall, R.F.; Cook, R.J.; Boronin, A.M. and Thomashow, L.S. (1998). A seven-gene locus for synthesis of phenazine-1-carboxylic acid by Pseudomonas fluorescens 2-79. Journal of Bacteriology, 180:2541-2548.

Mayhall, J. T. (1997). Dental anthropology. American Journal of Physical Anthropology, 104:535-536.

McGowan, R.P.; Cheng, K.L.; Bailey, C.B.M. and Costerton, J.W. (1988). Adhesion of bacteria to epithelial cell surfaces within reticulo-rumen of cattle. Applied Environmental Microbiology, 35:149-155.

Mehrotra, P. (2016). Biosensors and their applications: A review. Journal of Oral Biology and Craniofacial Research, 6:153-159.
Meyer, J.M. (2000). Review Pyoverdines: Pigments, siderophores and potential taxonomic markers of fluorescent Pseudomonas species. Archives of Microbiology, 174:135-42.

Miao, F.P.; Li, X.D.; Liu, X.H.; Cichewicz, R.H. and Ji, N.Y. (2012). Secondary metabolites from an algicolous Aspergillus versicolor strain. Marine Drugs, 10:131-139.

Migula, W. (1900). System der Bakterien, vol 2. Gustav Fischer, Jena, Germany.

Moore, E.R.B.; Tindall, B.J.; Martins, V.A.P.; Pieper, D.H.; Juan-Luis, R. and Palleroni, N.J. (2006). Nonmedical: Pseudomonas. Prokaryotes, 6:646-703.

Moore, N.M. and Flaws, M.L. (2011). Antimicrobial resistance mechanisms in Pseudomonas aeruginosa. Clinical laboratory scientist, 24:47-51.

Moss, M. (2002). Bacterial pigments. Microbiologist, 3:10-12.

Mukherjee, P.K. and Kenerley, C.M. (2010). Regulation of morphogenesis and biocontrol properties in Trichoderma virens by a velvet protein, vel1. Applied and Environmental Microbiology, 76:2345-2352.

Muller, M.; Li, Z. and Maitz, P.K. (2009). Pseudomonas pyocyanin inhibits wound repair by inducing premature cellular senescence: role for p38 mitogen-activated protein kinase. Burns, 35:500-508.

Murphy, T.F. (2008). The many faces of Pseudomonas aeruginosa in chronic obstructive pulmonary disease. Clinical Infectious Diseases, 47:1534-1536.

Nagia, F.A. and El-Mohamedy, R.S.R. (2007). Dyeing of wool with natural anthraquinone dyes from Fusarium oxysporum. Dyes Pigments, 75:550-555.

Nagpal, N.; Munjal, N. and Chatterjee, S. (2011). Microbial Pigments with Health Benefits: A mini review. Trends in Biosciences, 4:157-160.

Narenkumar, J.; Sathishkumar, K.; Sarankumar, R.K.; Murugan, K. and Rajasekar, A. (2017). An anticorrosive study on potential bioactive compound produced by Pseudomonas aeruginosa TBH2 against the biocorrosive bacterial biofilm on copper metal. Journal of Molecular Liquids, 243:706-713.

Narsing Rao, M.P; Xiao, M. and Li, W.J. (2017). Fungal and Bacterial Pigments: Secondary metabolites with wide application. Frontier Microbiology, 8:1113. doi: 10.3389/fmicb.2017.01113.

Ng, W.L. and Bassler, B.L. (2009). Bacterial quorum-sensing network architectures. Annual Reviews of Genetics, 43:197-222.

Nishi, T. and Forgac, M. (2002). The vacuolar HC-ATPases-nature's most versatile proton pumps. Nature Reviews Molecular Cell Biology, 3:94-103.

NNIS, system. (1999). National nosocomial infection surveillance system report. American Journal of Infection Control, 27:520-532.

O'Loughlin, C.T.; Miller, L.C.; Siryaporn, A.; Drescher, K.; Semmelhack, M.F. and Bassler, B.L. (2013). A quorum-sensing inhibitor blocks $P$. aeruginosa virulence and biofilm formation. Proceedings of the National Academy of Science USA, 110:17981-17986.

Oblinger, J.C. and Kreft, A.A. (1990). Inhibitory effect of Pseudomonas on selected Salmonella and bacterial isolates from poultry. Journal of Food Science, 35:30-32

Ohfuji, K.; Sato, N.; Hamada-Sato, N.; Kobayashi, T.; Imada, C. and Okuma, H. (2004). Construction of a glucose sensor based on a screen-printed electrode and a novel mediator pyocyanin from Pseudomonas aeruginosa. Biosensors and Bioelectronics, 19:1237-1244.

O'Malley, Y.Q; Abdalla, M.Y.; McCormick, M.L.; Reszka, K.J.; Denning, G.M. and Britigan, B.E. (2003). Subcellular localization of Pseudomonas pyocyanin cytotoxicity in human lung epithelial cells. American Journal of Physiology-Lung Cellular and Molecular Physiology, 284:420-430. 
Ostedgaard, S.; Baldursson, O.; Vermeer, D.; Welsh, M. and Robertson, A. (2001). Regulation of the cystic fibrosis transmembrane conductance regulator $\mathrm{ClK}$ channel by its $\mathrm{R}$ domain. Journal of Biological Chemistry, 276:7689-7692.

Otta, S.K.; Karunasagar, I. and Karunasagar, I. (1999). Bacterial flora associated with shrimp culture ponds growing Penaeus monodon. Journal of Aquaculture in the Tropics, 14:309-318.

Pai, S.S.; Anas, A.; Jayaprakash, N.S.; Priyaja, P.; Sreelakshmi, B.; Preetha, R.; Philip, R.; Mohandas, A. and Singh, I.S.B. (2010). Penaeus monodon larvae can be protected from Vibrio harveyi infection by pre-emptive treatment of a rearing system with antagonistic or non-antagonistic bacterial probiotics. Aquaculture Research, 4:847-860.

Parekh, S.; Vinci, V.A. and Strobel, R.J. (2000). Improvement of microbial strains and fermentation processes. Applied Microbiology and Biotechnology, 54:287-301.

Parsons, J.F.; Greenhagen, B.T.; Shi, K.; Calabrese, K.; Robinson, H. and Ladner, J.E. (2007). Structural and functional analysis of the pyocyanin biosynthetic protein PhzM from Pseudomonas aeruginosa. Biochemistry, 46:1821-1828.

Patil, S.; Nikama, M.; Patila, H.; Anokhinab, T.; Kochetkovb, V. and Chaudharia, A. (2017). Bioactive pigment production by Pseudomonas spp. MCC 3145: Statistical media optimization, biochemical characterization, fungicidal and DNA intercalation-based cytostatic activity. Process Biochemistry, 58:298-305.

Paul, J.P. (2018). Principles and practice of pediatric infectious diseases Eds: Long, S.S., Prober, C.G. and Fischer, M., 5th Edition, Elsvier.

Peix, A.; Berge, O.; Rivas, R.; Abril, A. and Velazquez, E. (2005). Pseudomonas argentinensis sp. nov., a novel yellow pigment producing bacterial species, isolated from rhizospheric soil in Cordoba, Argentina. International Journal of Systematic and Evolutionary Microbiology, 55:1107-1112.

Pierson, L.S. and Pierson, E.A. (2010). Metabolism and function of phenazines in bacteria: Impacts on the behavior of the bacteria in the environment and biotechnological process. Applied Micorbiology and Biotechnology, 18:1659-1670.

Powers, H.J. (2003). Riboflavin (vitamin B-2) and health. The American Journal of Clinical Nutrition, 77:1352-1360.

Prince, A.S. (2012). Pseudomonas aeruginosa. Principles and practice of pediatric infectious diseases. Editor: Sarah S. Long, 4th edition: $842-846$.

Priyaja, A. (2013). Pyocyanin (5-methyl-1-hydroxyphenazine) produced by Pseudomonas aeruginosa as antagonist to vibrios in aquaculture: Over-expression, downstream process and toxicity, Ph.D thesis, Cochin University of Science and Technology, India.

Priyaja, P.; Jayesh, P.; Correya, N.; Sreelakshmi, B.; Sudheer, N. and Philip, R. (2014). Antagonistic effect of Pseudomonas aeruginosa isolates from various ecological niches on Vibrio species pathogenic to crustaceans. Journal of Coastal Life Medicine, 2:76-84.

Rabaey, K. and Rozendal, R.A. (2010). Microbial electrosynthesis-revisiting the electrical route for microbial production. Nature Reviews Microbiology, 8:706-716.

Rabaey, K.; Boon, N.; Hofte, M. and Verstraete, W. (2005). Microbial phenazine production enhances electron transfer in biofuel cells. Environmental Science and Technology, 39:3401-3408.

Rahman, P.; Pasirayi, G.; Auger, V. and Ali, Z. (2009). Development of a simple and low cost microbioreactor for high-throughput bioprocessing. Biotechnology Letters, 31:209-214

Raisainen, R.; Nousiainen, P. and Hynninen, P.H. (2002). Dermorubin and 5chlorodermorubin natural anthraquinone carboxylic acids as dyes for wool. Textile Research Journal, 72:973-976.
Ran, H.; Hassett, D.J. and Lau, G.W. (2003). Human targets of Pseudomonas aeruginosa pyocyanin. PNAS Microbiology, 100:14315-14320.

Rani, A.; Chauhan, S. and Azmi, W. (2018). Production and antimicrobial, antioxidant and anticancer applications of pyocyanin from isolated Pseudomonas aeruginosa. SciFed Journal of Fermentation and Microbial Technology, 1:2.

Rashid, M.I. and Andleeb, S. (2018). Pyocyanin yield improvement for enhancement of Pseudomonas aeruginosa inoculated microbial fuel cell efficiency. International Conference on Power Generation Systems and Renewable Energy Technologies (PGSRET), pp:10-12. Sept. 2018, Islamabad, Pakistan, doi: 10.1109/PGSRET.2018.8685940.

Reimer, A. (2000). Concentrations of the Pseudomonas aeruginosa toxin pyocyanin in human ear secretions. Acta oto-laryngologica Supplementum, 543:86-88.

Rello, J.; Gallego, M.; Mariscal, D.; Sonora, R. and Valles, J. (1997). The value of routine microbial investigation in ventilator-associated pneumonia. American Journal of Respiratory and Critical Care Medicine, 156:196200 .

Rengpipat, S.; Rukpratanporn, S.; Piyatiratitivorakul, S. and Menasaveta, P. (2000). Immunity enhancement in black tiger shrimp (Penaeus monodon) by a probiont bacterium (Bacillus S11). Aquaculture, 191:271-288.

Reszka, K.J.; O' Malley, Y.; McCormick, M.L.; Denning, G.M. and Britigan, B.E. (2004). Oxidation of pyocyanin, a cytotoxic product from Pseudomonas aeruginosa, by microperoxidase 11 and hydrogen peroxide. Free Radical Biology and Medicine, 36:1448-1459.

Ricciardolo, F.L.; Stefano, A.D.; Sabatini, F. and Folkerts, G. (2006). Reactive nitrogen species in the respiratory tract. The European Journal of Pharmaceutical Sciences, 533:240-252.

Romer, A. and Herbert, R.B. (1982). Further observations on the source of nitrogen in phenazine biosynthesis. Zeitschrift für Naturforschung C, 37:1070-1074.

Ryazanova, O.; Voloshin, I.; Makitru, K.; Zozulya, V. and Karachevtsev, V. (2007). $\mathrm{pH}$-induced changes in electronic absorption and fluorescence spectra of phenazine derivatives spectrochim. Acta A Molecular and BioMolecular Spectroscopy, 66:849-859.

Saha, S.; Thavasi, R. and Jayalakashmi, S. (2008). Phenazine pigments from Pseudomonas aeruginosa and their application as antibacterial agent and food colourants. Research Journal of Microbiology, 3:122-128.

Sasidharan, A.; Sasidharan, N.K.; Amma, D.B.; Vasu, R.K.; Nataraja, A.V. and Bhaskaran, K. (2015). Antifungal activity of violacein purified from a novel strain of Chromobacterium sp. NIIST (MTCC 5522). Journal of Microbiology, 53:694-701.

Schaber, J.A.; Carty, N.L.; McDonald, N.A.; Graham, E.D.; Cheluvappa, R.; Griswold, J.A. and Hamood, A.N. (2004). Analysis of quorum sensingdeficient clinical isolates of Pseudomonas aeruginosa. Journal of Medical Microbiology, 53:841-853.

Schobert, M. and Jahn, D. (2010). Anaerobic physiology of Pseudomonas aeruginosa in the cystic fibrosis lung. International Journal of Medical Microbiology, 300:549-556.

Schroeter, J. (1872). Ueber einige durch Bacterien gebildete Pigmente. in: F. Cohn, Beitrage zur Biologie der Pflanzen, LBand, 2. Heft, 109-126.

Shen, H.B.; Yong, X.Y.; Chen, Y.L.; Liao, ZH.; Si, R.W.; Zhou, J.; Wang, SY.; Yong, Y.C.; OuYang, P.K. and Zheng, T. (2014). Enhanced bioelectricity generation by improving pyocyanin production and membrane permeability through sophorolipid addition in Pseudomonas aeruginosa-inoculated microbial fuel cells. Bioresource Technology, 167:490-494. 
Smith, E.E.; Buckley, D.G.; Wu, Z.; Saenphimmachak, C.; Hoffman, L.R.; D'Argenio, D.A.; Miller, S.I.; Ramsey, B.W.; Speert, D.P.; Moskowitz, S.M.; Burns, J.L.; Kaul, R. and Olson, M.V. (2006). Genetic adaptation by Pseudomonas aeruginosa to the airways of cystic fibrosis patients. Proceedings of the National Academy of Science USA, 103:8487-8492.

Sudhakar, T.; Karpagam, S. and Shiyama, S. (2013). Analysis of pyocyanin compound and its antagonistic activity against phytopathogens. International Journal of ChemTech Research, 5:1101-1106.

Sugita, H.; Hirose, Y.; Matsuo, N. and Deguchi, Y. (1998). Production of the antibacterial substance by Bacillus sp. strain NM 12, an intestinal bacterium of Japanese coastal fish. Aquaculture, 165:269-280.

Suthar, S.; Chhimpa, V. and Singh, S. (2009). Bacterial contamination in drinking water: A case study in rural areas of northern Rajasthan, India. Enviromental Monitoring and Assesment, 159:43-50.

Sweden, E.G. (2010). Study the effect of antibiotics on pyocyanin production from Pseudomonas aeruginosa and pyocyanin as antibiotic against different pathogenic bacteria. Journal of University of Anbar for Pure Science, 4:15-18.

Takahashi, J.A. and Carvalho, S.A. (2010). Nutritional potential of biomass metabolites from filamentous fungi. Current Research, Technology and Education Topics in Applied Microbiology and Microbial Biotechnology, 1126-1135.

Thompson, F.L.; Hoste, B.; Vandemeulebroecke, K. and Swings, J. (2001). Genomic diversity amongst Vibrio isolates from different sources determined by fluorescent amplified fragment length polymorphism. Systematic and Applied Microbiology, 24:520-538.

Tibor, C. (2006). Liquid chromatography of natural pigments and synthetic dyes. Journal of Chromatography Library, 7:602-611.

Unagul, P.; Wongsa, P.; Kittakoop, P.; Intamas, S.; Srikiti, K. and Tanticharoen, M. (2005). Production of red pigments by the insect pathogenic fungus Cordeycepsuni lateralis BCC 1869. Journal of Industrial and Microbial Biotechnology, 32:135-140.

Usher, L.; Lawson, R.; Gaery, I.; Taylor, C.; Bingle, C.; Taylor, G. and Whyte, M. (2002). Induction of neutrophil apoptosis by the Pseudomonas aeruginosa exotoxin pyocyanin: A potential mechanism of persistent infection. The Journal of Immunology, 4:1861-1868.

Vandenberghe, J.; Thompson, F.L.; Gomez-Gil, B. and Swings, J. (2003) Phenotypic diversity amongst Vibrio isolates from marine aquaculture systems. Aquaculture, 219:9-20.

Verschuere, L.; Rombaut, G.; Sorgeloos, P. and Verstraete, W. (2000). Probiotic bacteria as biological control agents in aquaculture. Microbiology and Molecular Biology Reviews, 64:655-671.

Venil, C.K. and Lakshmanaperumalsamy, P. (2009). Prodigiosin: An insightful overview on microbial pigment. Electronic Journal of Biology, 5: 49-61.

Verdonck, L.; Grisez, L.; Sweetman, E.; Minkoff, G.; Sorgeloos, P.; Ollevier, F. and Swings, J. (1997). Vibrios associated with routine productions of Brachionus plicatilis. Aquaculture, 149:203-214.

Vijayan, K.K.; Singh, I.S.B.; Jayaprakash, N.S.; Alavandi, S.V.; Pai, S.S.; Preetha, R.; Rajan, J.J.S. and Santiago, T.C. (2006). A brackish water isolate of Pseudomonas PS-102, a potential antagonistic bacterium against pathogenic vibrios in penaied and non-penaied rearing systems. Aquaculture, 251:192-200

Vincent, J.L.; Bihari, D.J.; Suter, P.M.; Bruining, H.A.; White, J.; Nicolas-Chanoin, M.H.; Wolff, M.; Spencer, R.C. and Hemmer, M. (1995). The prevalence of nosocomial infection in intensive care units in Europe. Results of the European Prevalence of Infection in Intensive Care (EPIC) Study. EPIC International Advisory Committee. The Journal of the American Medical Association, 274:639-644.

Waksman, S.A. and Woodruff, H.B. (1940). The soil as a source of microorganisms antagonistic to disease producing bacteria. Journal of Bacteriology, 40:581-600.
Wen, Q., Kong, F.; Ma, F. and Ren, Y. (2011). Improved performance of aircathode microbial fuel cell through additional Tween 80 . Journal of Power Sources, 196:899-904.

Williams, H. D.; Zlosnik, J.E. and Ryall, B. (2007). Oxygen, cyanide and energy generation in the cystic fibrosis pathogen Pseudomonas aeruginosa. Advances in Microbial Physiology, 52:1-71.

Wilson, R.; Sykes, D.A.; Rutman, A.; Taylor, G.W. and Cole, P.J. (1988). Measurement of Pseudomonas aeruginosa phenazine pigments in sputum and assessment of their contribution to sputum sol toxicity for respiratory epithelium. Infection and Immunity, 56:2515-2517.

Wilson, R.; Pitt, T.; Taylor, G.; Watson, D.; MacDermot, J.; Sykes, D.; Roberts, D. and Cole, P. (1987). Pyocyanin and 1-hydroxyphenazine produced by Pseudomonas aeruginosa inhibit the beating of human respiratory cilia in vitro. Journal of Clinical Investigation, 79: 221-229

Worlitzsch, D.; Tarran, R.; Ulrich, M.; Schwab, U.; Cekici, A.; Meyer, K.C.; Birrer, P.; Bellon, G.; Berger, J.; Weiss, T.; Botzenhart, K.; Yankaskas, J. R.; Randell, S.; Boucher, R. C. and Doring, G. (2002). Effects of reduced mucus oxygen concentration in airway Pseudomonas infections of cystic fibrosis patients. Journal of Clinical Investigation, 109:317-325.

Wu, H.; Moser, C.; Wang, H.Z.; Hoiby, N. and Song, Z.J. (2015). Strategies for combating bacterial biofilm infections. International Journal of Oral Science, 7:1-7.

Wulf, B. and Parsons, J.F. (2014). The structural biology of phenazine biosynthesis. Current Opinion in Structural Biology, 29:26-33.

Yada, S.; Wang, Y.; Zou, Y.; Nagasaki, K.; Hosokawa, K.; Osaka, I.; Arakawa, R. and Enomoto, K. (2007). Isolation and characterization of two groups of novel marine bacteria producing violacein. Marine Biotechnology, 10:128-132.

Yang, Z.J.; Wang, W.; Jin, Y.; Hu, H.B.; Zhang, X.H. and Xu, Y.Q. (2007). Isolation, identification, and degradation characteristics of phenazine-1carboxylic acid degrading strain Sphingomonas sp. DP58. Current Microbiology, 55:284-287.

Yong, X.Y.; Feng, J.; Chen, Y.L.; Shi, D.Y.; Xu, Y.S.; Zhou, J.; Wang, S.Y.; Xu, L.; Yong, Y.C. and Sun, Y.M. (2014a). Enhancement of bioelectricity generation by cofactor manipulation in microbial fuel cell. Biosensors and Bioelectronics, 56:19-25.

Yong, Y.C.; Yu, Y.Y.; Li, C.M.; Zhong, J.J. and Song, H. (2011). Bioelectricity enhancement via overexpression of quorum sensing system in Pseudomonas aeruginosa inoculated microbial fuel cells. Biosensors and Bioelectronics, 30:87-92.

Yong, Y.C.; Yu, Y.Y.; Yang, Y.; Liu, J.; Wang, J.Y. and Song, H. (2013). Enhancement of extracellular electron transfer and bioelectricity output by synthetic porin. Biotechnology and Bioengineering, 110:408-416.

Yong, X.Y.; Shi, D.Y.; Chen, Y.L.; Jiao, F.; Lin, X.; Zhou, J.; Wang, S.Y.; Yong, Y.C.; Sun, Y.M. and OuYang P.K. (2014b). Enhancement of bioelectricity generation by manipulation of the electron shuttles synthesis pathway in microbial fuel cells. Bioresource Technology, 152: $220-224$.

Young, G. (1947). Pigment production and antibiotic activity in cultures of Pseudomonas aeruginosa. Journal of Bacteriology, 54:109-117.

Zhao, J.; Wu, Y.; Alfred, A.T.; Wei, P. and Yang, S. (2014). Anticancer effects of pyocyanin on HepG2 human hepatoma cells. Letters of Applied Microbiology, 58:541-548.

Zhu, H.H.; Guo, J.; Yao, Q.; Yang, S.Z; Deng, M.R.; Phuong le, T.B.; Hanh, V.T. and Ryan, M.J. (2007). Streptomyces vietnamensis sp. nov., a streptomycetes with violet blue diffusible pigment isolated from soil in Vietnam. International Journal of Systematic and Evolutionary Microbiology, 57:1770-1774

Citation: Alka Rani and Wamik Azmi (2019). An overview on biosynthesis and applications of extracellular pyocyanin pigment and its role in Pseudomonas aeruginosa pathogenesis. Ann. Phytomed., 8(2):28-42. 